\title{
Genome wide-association study identifies novel loci in the Primary Open-Angle African American Glaucoma Genetics (POAAGG) study
}

Harini V. Gudiseva MS ${ }^{1 *}$, Shefali Setia Verma $\mathrm{PhD}^{2 *}$, Venkata R. M. Chavali $\mathrm{PhD}^{1}$, Rebecca J. Salowe MSE ${ }^{1}$, Anastasia Lucas ${ }^{2}$, David W. Collins BA ${ }^{1}$, Sonika Rathi PhD ${ }^{1}$, Jie He MD ${ }^{1}$, Roy Lee $\mathrm{MS}^{1}$, Sayaka Merriam BA ${ }^{1}$, Anita S. Bowman MS ${ }^{1}$, Caitlin P. McHugh $\mathrm{PhD}^{3}$, Michael C. Zody $\mathrm{PhD}^{3}$, Maxwell Pistilli MS ${ }^{1}$, Naira Khachataryan $\mathrm{MD}^{1}$, Ebenezer Daniel $\mathrm{PhD}^{1}$, Windell Murphy MD ${ }^{4}$, Mark Weiner MD ${ }^{5}$, Jeffrey Henderer MD ${ }^{5}$, Ahmara Ross MD PhD ${ }^{1}$, Qi N. Cui MD PhD ${ }^{1}$, Victoria Addis MD ${ }^{1}$, Amanda Lehman MD ${ }^{1}$, Eydie Miller-Ellis MD ${ }^{1}$, Prithvi S. Sankar $\mathrm{MD}^{1}$, Rohit Varma $\mathrm{MD}^{6}$, Scott M. Williams $\mathrm{PhD}^{7}$, Gui-shuang Ying $\mathrm{PhD}^{1}$, Jason H. Moore $\mathrm{PhD}^{8}$, Marylyn D. Ritchie $\mathrm{PhD}^{2}$, Joan M. O'Brien $\mathrm{MD}^{1 * *}$

*These authors contributed equally to the work.

${ }^{1}$ Scheie Eye Institute, University of Pennsylvania, Philadelphia, PA, USA.

${ }^{2}$ Department of Genetics, University of Pennsylvania, Philadelphia, PA, USA.

${ }^{3}$ New York Genome Center, New York City, NY, USA.

${ }^{4}$ Windell Murphy, MD, Philadelphia, PA, USA.

${ }^{5}$ Lewis Katz School of Medicine at Temple University, Philadelphia, PA, USA.

${ }^{6}$ Keck School of Medicine, University of Southern California, Los Angeles, CA, USA

${ }^{7}$ Department of Population and Quantitative Health Sciences, Case Western Reserve University, Cleveland, OH, USA.

${ }^{8}$ Institute for Biomedical Informatics, University of Pennsylvania, Philadelphia, PA, USA.

**Corresponding Author: Scheie Eye Institute, 51 N. 39th Street, Philadelphia, PA 19104

(joan.obrien@uphs.upenn.edu; phone: 215-662-8657; fax: 215-662-9676)

Financial Support: This work was supported by the National Eye Institute, Bethesda, Maryland (grant \#1RO1EY023557-01) and Vision Research Core Grant (P30 EY001583). Funds also come from the F.M. Kirby Foundation, Research to Prevent Blindness, The UPenn Hospital Board of Women Visitors, and The Paul and Evanina Bell Mackall Foundation Trust. The Ophthalmology Department at the Perelman School of Medicine and the VA Hospital in Philadelphia, PA also provided support. The sponsor or funding organization had no role in the design or conduct of this research. 


\begin{abstract}
$\underline{\text { Abstract }}$
Primary open-angle glaucoma (POAG), the leading cause of irreversible blindness worldwide, disproportionately affects African Americans. Large-scale POAG genetic studies have focused on individuals of European and Asian ancestry, limiting our understanding of disease biology. Here we report genetic analysis of the largest-ever deeply phenotyped African American population ( $\mathrm{n}=5950)$, identifying a novel POAG-associated SNP on chromosome 11 near the TRIM66 gene (rs112369934). POAG trait association also implicated SNPs in genes involved in trabecular meshwork homeostasis and retinal ganglion cell maintenance. These new loci deepen our understanding of the pathophysiology of POAG in African Americans.
\end{abstract}




\section{$\underline{\text { Introduction }}$}

Primary open-angle glaucoma (POAG) is an insidious neurodegenerative disease of the optic nerve that causes progressive loss of vision. ${ }^{1}$ This disease affects 44 million individuals worldwide, with a projected prevalence of 53 million cases by 2020 and 80 million cases by $2040 .^{2}$ It is estimated that up to 6 million individuals will be bilaterally blind from POAG by $2020 .{ }^{3}$ A disproportionately large percentage of these individuals will be of African descent. ${ }^{3}$ African Americans are four to five times more likely be affected by POAG than European Americans ${ }^{4}$ - and up to 15 times more likely to experience vision loss from the disease. ${ }^{5}$ This population is also diagnosed at a younger age with more severe and rapidly progressive symptoms. ${ }^{6,7}$

Aside from African ancestry, the major risk factors for POAG include advanced age, elevated intraocular pressure (IOP), and family history of glaucoma. ${ }^{8}$ Several studies have also reported greater disease risk among males. ${ }^{9-11}$ Of these risk factors, elevated IOP is the only treatable component of the disease, with current treatments aiming to lower IOP to a level that slows or halts optic nerve degeneration. ${ }^{12,13}$ However, this therapeutic approach is frequently not sufficient to halt disease progression, suggesting that POAG has additional underlying disease mechanisms that could be elucidated by large-scale genetic studies. ${ }^{14,15}$

Many twin and family history studies have established that POAG has a strong genetic component, ${ }^{16-19}$ yet more than $90 \%$ of its genetics remain unexplained. ${ }^{20}$ This remaining $10 \%$ is due to variants with small individual effect sizes in genes such as MYOC, OPTN, WDR36, CDK2N2B-AS1, TMCO1, SIX6, ABCA1, GAS7, FOXC1, NTF4, ASB10, EFEMP1, and IL2ORB. ${ }^{20-}$

${ }^{23}$ However, most of these loci do not replicate in African Americans. The majority were discovered in populations of European, ${ }^{24-28}$ Chinese $^{29}$, and Japanese ${ }^{30-34}$ descent or large meta- 
analyses of these groups, ${ }^{23,28,35}$ and have greatly reduced or unknown role in African Americans. ${ }^{36-}$ 38

A limited number of studies have investigated glaucoma genetics in African Americans. A multi-ethnic genome-wide association study (GWAS) of the Genetic Epidemiology Research in Adult Health and Aging (GERA) cohort, which included individuals of African, Asian, Hispanic, and European descent, identified three novel and replicated variants near the PDE7B, TMCTC2, and FMNL2 genes. ${ }^{39}$ A GWAS of South African and African American populations identified a novel candidate locus on the EXOC4 gene, but it did not associate in a West African replication cohort. ${ }^{37}$ The African Descent and Glaucoma Evaluation Study (ADAGES) identified a novel association with advanced POAG and the ENO4 locus. ${ }^{40}$ Most recently, a GWAS identified a novel locus $(A P B B 2)$ that was significantly associated with POAG in individuals of African ancestry, but not of European or Asian ancestry. ${ }^{41}$ These studies have made important strides towards understanding POAG genetics in African ancestry individuals. They do not, however, address the need to investigate the disease in a deeply phenotyped cohort of African Americans.

Since POAG is a heterogeneous disease with a broad range of trait expression, it is also important to identify variants associated with specific endophenotypes. These findings can help to identify subgroups of disease and improve predictive models for development and progression. ${ }^{42,43}$ To date, several associations with structural features of the optic nerve head (such as cup-to-disc ratio, rim area, cup area, and total disc area) have been reported in genes such as $C D K N 2 B$, $S I X 1 / 6$, ATOH7, CDC7, and CHEK2. ${ }^{44-47}$ IOP has also been linked to a number of SNPs, particularly near the TMCO1, CAV1,CAV2, FNDC3B, and GAS7 genes. ${ }^{48-50}$ Finally, central corneal thickness (CCT) has shown associations with FOX01, ZNF469, COL5A, and FNDC3B. ${ }^{51-53}$ As in the genetic studies on POAG described above, the variants associated with quantitative traits were primarily 
identified in populations of European ancestry and require explicit investigation in African Americans.

We conducted a large-scale GWAS to identify variants of pathophysiological importance to POAG in African Americans $(n=5950)$ recruited from the city of Philadelphia, through a project entitled the Primary Open-Angle African American Glaucoma Genetics (POAAGG) study. ${ }^{54}$ This paper reports novel GWAS findings from overall case-control analysis, as well as genes associated with POAG endophenotypes. In addition, the functional relevance of significant findings from our study are verified using in silico analysis and in vitro studies in cell lines relevant to POAG.

\section{Results:}

\section{Case-control GWAS identifies potential novel associations with POAG}

We successfully genotyped 6525 DNA samples on the Multi-Ethnic Genotyping Array (MEGA) V2 (EX) consortium chip and Infinium iSelect platform using Illumina FastTrack Services (Illumina, San Diego, CA) (Methods). Genotyped samples and variants were subjected to rigorous quality control (QC), as illustrated in Extended Data Tables 1 and 2. Single SNP association analysis was performed on 5950 unrelated individuals, consisting of 2589 cases (males n=1103; females $n=1486$ ) and 3361 controls (males $n=1042$; females $n=2319$ ). Through a logistic regression model adjusted for age, sex, and population stratification, we identified a novel locus that reached genome-wide significance in all subjects on Chromosome (Chr.) 11:8702073 [Chr. 11p15.4, rs112369934; $P$ value $=2.01 \times 10^{-8} ;$ adjusted odds ratio $\left.(\mathrm{OR})=1.67\right]$, located nearest to the TRIM66 gene (Figure 1a).

We also investigated the association of variants in high linkage disequilibrium (LD) within the gene boundaries of previously associated GWAS SNPs for POAG $28,46,55-57$ (Fig. 2). Minimal 
significance was observed for $C D K N 2 B-A S 1$ (lowest $P$-value $=4.31 \times 10^{-7}$; OR $=0.65$ ) and with the downstream region of $A R H G E F 12$ (lowest $P$-value $=9.4 \times 10^{-8} ; \mathrm{OR}=1.27$ ) (Fig. 2).

\section{Quantitative traits highlight genetic heterogeneity of POAG in African Americans}

Because POAG is a heterogeneous disease with diverse clinical presentations, we also conducted association analyses with glaucoma-related quantitative phenotypes for both eyes in cases and controls (Methods). Assuming independence of tests, the genome-wide quantitative trait association studies of seven distinct POAG phenotypic features identified 260 SNP-trait associations (p-value $<5 \times 10^{-8}$ ) in 127 genomic regions (Extended Table 3). A total of 30 variants reached genome-wide significance for cup-to-disc ratio (CDR), as well as 21 variants for intraocular pressure (IOP) baseline, 30 for IOP maximum (the highest IOP measure available in baseline and latest data), 43 variants for baseline pattern standard deviation (PSD), 129 variants for baseline mean deviation (MD), and one variant for retinal nerve fiber layer (RNFL) thickness (Fig. 3). SNP association results for visual acuity (VA logMAR case-control association analysis) and central corneal thickness (CCT) did not reach conservative genome-wide wide significance, assuming independence of variants and all phenotypes evaluated in this study.

A subset of the significant SNPs $(n=18)$ mapped to genes with published POAG and phenotype association and localization in ocular tissue data, as highlighted in Table 1. We identified several genes associated with the CDR phenotype at $C X C R 7 / A C K R 3, M P D Z$, and ADAM12. IOP baseline and maximum were both associated with COL15A1 and DNM3. We also identified significant SNPs associated with MD in the LMX1B gene and COL19A1 gene. Two different variants in the PAK1 gene were independently associated with the MD and PSD phenotypes (Table 1, Extended Table 3). 


\section{Gene-set association analysis using MAGMA}

We performed gene-based analysis using the MAGMA tool to identify additional regions of interest. Gene-based p-values were calculated based on mean SNP-association p-values. This analysis indicated $C L C F 1$ ( $\mathrm{p}$-value $=1.04 \times 10^{-6}$ ) as a significant gene for POAG after multiple hypothesis correction (Figure 1a). Quantitative traits-based MAGMA analyses identified six significant associations among all traits (Figure 3). CCT latest was associated with DNAJC5B (gene-based $P$-value $=1.61 \times 10^{-7}$ ) and VA logMAR case control status was associated with FAM209A (gene-based $P$-value $\left.=1.88 \times 10^{-6}\right) . S T X B P 3\left(\right.$ gene- based $P$-value $\left.=9.05 \times 10^{-8}\right), L A M B 1$ (gene-based $P$-value $\left.=1.07 \times 10^{-6}\right)$, and $T L N 2\left(\right.$ gene-based $\mathrm{P}$-value $\left.=1.0 \times 10^{-6}\right)$ were associated with baseline MD, and CMTR (gene-based $P$-value $=3.74 \times 10^{-8}$ ) and KRT37 (gene-based $P$-value $=1.46$ $\mathrm{x} 10^{-6}$ ) were associated with baseline PSD. None of the gene-set based association results overlapped with the genes mapping to SNPs from the single variant association tests.

\section{$\underline{\text { In silico analysis suggests genes with possible role in POAG }}$}

To understand and prioritize POAG-associated SNPs and genes for additional studies, we assessed the expression levels of genes containing significantly associated variants in silico wherever data were available. We used two publicly available databases: 1) Ocular Tissue Database (OTDB) with human eye tissue expression, ${ }^{58}$ and 2) the IOP-induced mouse optic nerve head (ONH) microarray gene expression dataset [Glaucoma Discovery Platform (GDP)]. ${ }^{59}$ As there is no ocular tissue information in GTEx or ENCODE databases, we did not utilize them for determining gene expression. In the OTBD, all SNP-associated genes from our study were expressed in eye tissues, including trabecular meshwork (TM) cells, the $\mathrm{ONH}$, optic nerve $(\mathrm{ON})$ tissues, and the retina 
(Table 2a). Compared to other genes, MPDZ had the highest expression in the majority of ocular tissues, specifically in the lens, ON, ONH, and TM, while PAK1 expression was lowest in the ON, ONH, and TM. COL15A1, DNM3, and $L M X 1 B$ were moderately expressed in all ocular tissues.

Using GDP, we compared the transcriptomic profiles of the mouse ONH obtained from 9month-old D2 mice (an age-dependent model of IOP/glaucoma) with D2-Gpnmb+ mouse (control mice). We found increased expression of Adam12, Cxcr7, Col15al, and Anax2 in all stages of IOP-induced glaucoma, with almost two-fold overexpression in late stages (Table 2b). The expression of gene transcripts for Trim66, Dnm3, Pak1, Mpdz, and Col19al was lower when compared to the control mice in the early to moderate stages of glaucoma, while higher in stage 5 of glaucoma (Table 2b). The differential expression patterns of the above phenotype-associated genes during moderate to advanced stages of glaucoma indicates an important role in glaucoma pathogenesis.

Among the genes identified by MAGMA analysis, higher expression of STXBP3 was observed in all ocular tissues compared to other genes, specifically in the lens, ON, ONH, and TM (Extended Table 4a). LAMB1 was predominantly expressed in TM and cornea tissue. Differential upregulation of $C l c f 1$ was seen in Stage 3 and Stage 4 glaucoma in the mouse ONH. Tln2 (FDR, $\mathrm{q}<0.05)$ was found to be differentially downregulated in glaucoma from early to severe stages of the disease in the mouse ONH. None of the other MAGMA identified genes associated with POAG endophenotypes showed differential expression across any stage of glaucoma (Extended Data Table 4b).

\section{Expression of POAG-associated loci/genes in ocular cell lines after oxidative stress}


The pathogenesis of POAG involves apoptosis of retinal ganglion cells (RGCs) and damage to the TM caused by oxidative stress. ${ }^{60,61}$ To understand expression patterns and determine the functional relevance of POAG-associated genes under oxidative stress conditions, we induced oxidative stress in human ocular cell lines with $\mathrm{H}_{2} \mathrm{O}_{2}$ (Table 3). We quantified the expression profiles of POAG-associated genes in human TM cells (hTM) and RGCs derived from induced pluripotent stem cells (iPSC-RGCs) treated with $\mathrm{H}_{2} \mathrm{O}_{2}$. Increased expression of $\mathrm{SOD} 1$ at $650 \mathrm{uM} \mathrm{H}_{2} \mathrm{O}_{2}$ in iPSCRGCs (Table 3a) and at 100uM H $\mathrm{H}_{2} \mathrm{O}_{2}$ in hTM (Table 3b) indicates suitable concentrations of $\mathrm{H}_{2} \mathrm{O}_{2}$ for inducing oxidative stress conditions in these cell lines. Among all the genes tested, we found increased expression of ADAM12, COL15A1, DNM3, and TRIM66 in both iPSC-RGCs and hTM cells treated with $\mathrm{H}_{2} \mathrm{O}_{2}$ when compared to untreated cells. Expression of IL6, ANXA2, CXCR7, and PAK1 was downregulated in iPSC-RGCs, but upregulated in hTM after oxidative stress. LMX1B and COL19A1 were overexpressed in iPSC-RGCs, while in hTM cells, $L M X 1 B$ expression was suppressed after oxidative stress and COL19A1 was undetectable. This differential expression of genes identified by our GWAS in iPSC-RGCs and hTM cells indicates their role in the maintenance of cellular homeostasis in RGCs and hTM cells under stress conditions.

\section{Pathway analyses highlights heterogeneous nature of POAG}

Pathway analysis using ingenuity pathway analysis (IPA) (p-value<0.05, Table 4) showed that matrix metalloproteinase inhibition and tight junction signaling pathways were significant for CDR associated genes, while remodeling of adherens junction was moderately significant for IOP associated genes. Receptor signaling pathways such as DNA damage-induced signaling, Amyotrophic lateral sclerosis (ALS) signaling, synaptogenesis, Ephrin signaling, and genes associated with Pyridoxal 5' pathways that prevent ganglion cell loss due to ischemic retinal injury 
were significant for genes associated with MD and PSD in our study. ${ }^{62}$ Pathways identified by IPA analyses were not shared among any quantitative traits. Pathway analysis for genes obtained from MAGMA analysis identified genes in tight junction signaling, retinol biosynthesis, and coagulation as significant for the development of POAG (Table 4).

\section{$\underline{\text { Discussion }}$}

The majority of the genetic studies on POAG to date have been conducted in individuals of European and Asian ancestry. Our study recruited, genotyped, and deeply phenotyped the largest cohort of African Americans with POAG recruited from a single city, providing novel information on disease biology for this most affected population. The GWAS study in 5950 African Americans implicated four variants with higher risk of POAG, as well as 260 variants in 127 genomic regions with glaucoma-related endophenotypes.

In the case-control GWAS analysis, we identified one variant (rs112369934) located near the TRIM66 gene that reached genome-wide significance. TRIM66 belongs to the Tripartite motif (Trim) family of genes that are highly represented in the retinal progenitor cells (RPCs) in the developing mouse retina. ${ }^{63}$ We also used MAGMA software analysis to determine gene and gene-set based associations, which employs a multiple regression model. ${ }^{64}$ MAGMA analysis suggested CLCF1 as a significant gene for POAG in sex-combined case-control analysis. CLCF1 encodes an inflammatory cytokine, cardiotrophin like cytokine factor 1 protein (CLCF1). CLCF1 is a heterodimeric neurotropic cytokine that may play a role in the maintenance of RGC health in POAG. CLCF1 demonstrates both growth factor and neuroprotective effects on RGCs, ${ }^{65}$ and its expression has been associated with response to stress as observed in glaucoma. ${ }^{66}$ 
The GWAS analysis also confirmed the association of several previously associated POAG variants in other populations, including $C D K N 2 B-A S 1, A R H G E F 12$, and TMCO1, supporting the likelihood of their contribution to POAG. However, many previously associated loci identified in other ancestral populations did not replicate in our study. This is likely due to genetic heterogeneity across different ancestral groups. Because our study is the largest African American dataset available to date, no comparable ancestry-matched dataset was available to replicate these novel findings.

The genome-wide quantitative trait association studies of seven distinct POAG phenotypic features identified loci in 127 genomic regions. Further functional studies, tissue localization, and loss-of-function studies are necessary to fully understand the role of these genes in POAG. The CXCR7 gene associated with CDR is a chemokine receptor that controls the chemokine network. In glioma cells, $C X C R 7$ transduces signals via MEK/ERK pathway, mediating resistance to apoptosis by promoting cell growth and survival. ${ }^{67}$ The $M P D Z$ gene, also associated with CDR, encodes a multiple PDZ domain crumbs cell polarity complex protein. Novel variants in this gene were previously reported in a multi-ethnic Asian GWAS study to be associated with CCT but not with CDR. ${ }^{68}$ Increased expression of $A D A M 12-L$ was reported in TM cells in response to oxidative stress resulting from elevated IOP, causing RGC degeneration and affecting the CDR. ${ }^{69}$

IOP baseline and IOP maximum traits were both associated with the COL15A1 gene, which encodes the alpha chain of type XV collagen. A commonly reported variant in COL15A1, R163H is reported to influence the age of onset of POAG. ${ }^{70}$ RNA in situ hybridization of mouse eyes showed that Col15al was expressed in multiple ocular structures including the ciliary body, astrocytes of the $\mathrm{ON}$, and cells in the RGC layer. ${ }^{70}$ 
For the genes associated with visual fields, previous studies have shown that $L m x 1 b$ is needed for the formation of the TM and maintenance of corneal transparency in the mouse anterior segment. ${ }^{71}$ A dominant negative mutation of mouse $\operatorname{Lmx} 1 b\left(\operatorname{Lmx} 1 b^{I c s t /+}\right)$ also causes glaucoma and is semi-lethal. ${ }^{72}$ The COL19A1 gene encodes the alpha chain of type XIX collagen, a member of the FACIT collagen family (fibril-associated collagens with interrupted helices). Decreased expression of Col19A1 (1.9 fold) was observed in a microarray of an 8-month old DBA/2J mouse retina when compared to 3-month-old retina. This suggests the encoded protein may play a role in the maintenance of the cytoskeletal matrix as a result of prolonged IOP elevation in the older mice, which can result in ganglion cell loss. ${ }^{73}$ The PAK1 gene encodes a family member of serine/threonine p21-activating kinases, known as PAK proteins. ${ }^{74}$ PAK1 is inactivated by oxidative stress conditions and oxidative stress-induced down-regulation of PAK1 activity could be involved in the loss of mesencephalic dopaminergic (DA) neurons through modulation of neuronal death in Parkinson's disease, ${ }^{75}$ suggesting that the PAK1 protein may have a role in neuroprotection.

Our study identified genes that have significantly altered expression in TM cells (ADAM12, COL19A1, DNM3, and TRIM66), suggesting that these genes may play a role in pathways leading to TM cell damage or altered homeostasis. Inflammatory pathway genes identified in our study including IL6, ANXA2, COL15A1, CXCR7, DNM3, and PAK1 exhibit gene transcripts that were significantly overexpressed in iPSC-RGCs treated with hydrogen peroxide, indicating that these genes may be involved in maintaining RGC health and could play a role in glaucomatous neurodegeneration. These findings are also supported by our IPA analysis performed using the implicated genes from this study. 
As this is the first large effort to study the genetic basis of POAG in a deeply phenotyped African American cohort, the findings we present here must be replicated in future cohorts. Notably, associations from the glaucoma binary (case-control) phenotype are different than the associations with quantitative traits in cases and controls, likely reflecting heterogeneity in the underlying genetic etiologies of glaucoma. A recently published GWAS on individuals of African ancestry identified a variant on chromosome 4 (rs59892895) linked with POAG case-control status. ${ }^{41}$ This association did not replicate in our study (p-value=0.335). Additionally, our genomewide significant SNP from case-control analyses (rs112369934) was not available in summary statistics in this published study. Differences between the GWAS findings in other POAG cohorts should be examined carefully, and follow-up analyses should consider genetic ancestry when interpreting these differences. Our study investigated African Americans, which is a more admixed population compared to the African descent individuals. ${ }^{76,77}$ Additional analyses will help validate the biological implications of the variants discovered from the POAAGG study.

Enviornmental factors can play a confounding role in power to detect associations. Strengths of this study include the recruitment of African Americans solely from Philadelphia, allowing us to control for differences in environment and socioeconomic factors, possibly increasing statistical power to detect GWAS associations. This study also employed the MEGA array, which had custom content designed through selective whole-genome sequencing, maximizing coverage of variants relevant for genomic analysis of admixed populations. We carefully ascertained endophenotypes from each subject, which is crucial to prevent residual confounding effects of unmeasured phenotypes within association studies. ${ }^{78}$

A limitation of this study is that the genetic variation in African Americans is greater than that observed in European Americans, ${ }^{79}$ limiting power to detect SNP effects in a GWAS analysis 
and necessitating a larger cohort to detect significant associations. However, the POAAGG study as a whole presents a unique opportunity to examine an admixed population, potentially leading to novel discoveries that may not be apparent in studies that focus on samples with homogeneous ancestry. Another limitation is the lack of replication of our significant associations from the quantitative traits; however, to our knowledge, no African ancestry dataset with similar endophenotypes is available yet.

In conclusion, this study greatly expands knowledge of the genetic underpinnings of POAG in African Americans. Future analyses will help validate the biological implications of the variants discovered from this study, and have potential application to screening and treating this overaffected population.

\section{Methods}

\section{Subjects}

\section{Eligibility Criteria}

The POAAGG study population consists of self-identified blacks (African American, African descent, or African Caribbean), aged 35 years or older. Exclusion criteria included a history of narrow angle, closed angle, neovascular, mixed mechanism, or pseudoexfoliation glaucoma; history of glaucoma secondary to eye surgery or secondary to severe ocular trauma; history of iritis, uveitis, or iridocyclitis; presence of Grave's disease with ocular manifestations, vascular occlusion causing neovascularization of the iris, optic nerve atrophy from other diagnoses, or advanced proliferative diabetic retinopathy. All subjects provided informed written consent, in accordance with the tenets of the Declaration of Helsinki, under IRB-approved protocols. 


\section{Study Procedures}

Study participants were identified from within all comprehensive and subspecialty ophthalmology clinics at the University of Pennsylvania (Scheie Eye Institute, Perelman Center for Advanced Medicine, Mercy Fitzgerald Hospital, VA Hospital); Lewis Katz School of Medicine at Temple University; Drexel University College of Medicine; and a private practice (Windell Murphy, MD). The clinical examination included an onsite ophthalmic exam and interview. Examination data were entered directly into the Research Electronic Data Capture (REDCap) database utilized at University of Pennsylvania (UPenn). ${ }^{80}$ Data collection was standardized and included a series of measurements taken analyzed glaucoma specialists.

The full onsite exam included: (1) verification of name, age, date of birth, street address, gender, and informed consent with signature; (2) completion of a health and family history questionnaire in-clinic including evaluation of diabetes and/or high blood pressure diagnoses, ocular surgical history, family history of glaucoma, and tobacco and alcohol use (confirmed in medical record when possible); (3) evaluation of height and weight; (4) explanation of procedure for blood or saliva collection for DNA analysis; (5) visual acuity measured using Snellen chart at 20 feet; (6) automated refraction with a Reichert Phoropter RS Automatic Refractor (Reichert Technologies, Depew, NY) if the presented visual a acuity was not 20/20 in either eye, followed by manual refraction; (7) near vision assessed using the Snellen chart at near with the participant's current reading prescription; (8) intraocular pressure measured with a Goldmann applanation tonometer; (9) anterior and posterior segment examinations by slit lamp with a 90-diopter lens; (10) gonioscopy; (11) central corneal thickness and axial length measurements assessed with an ultrasonic A-scan/pachymeter DGH 4000B SBH IOL Computation module (DGH Tech Inc., Exton, PA); (12) visual field test utilizing the Humphrey Automated Field Analyzer (Standard 24- 
2 Swedish interactive thresholding algorithm); (13) stereo disc photos and fundus photography utilizing the Topcon TRC 50EX Retinal Camera (Topcon Corp. of America, Paramus, NJ); and (14) optical coherence tomography (OCT) using either Cirrus or Stratus OCT (Carl Zeiss Meditec, Dublin, CA) or iVue (Optovue, Fremont, CA) . The outcomes of the procedures and all diagnoses were discussed with the patient at the conclusion of the examination.

\section{Phenotyping}

Cases and controls were selected from the UPenn patient population based on the following criteria: Primary open-angle glaucoma (POAG) cases were defined as having an open iridocorneal angle and: (1) characteristic glaucomatous optic nerve findings in one or both eyes consisting of at least one of the following: notching, neuroretinal rim thinning, excavation, or a nerve fiber layer defect; (2) characteristic visual field defects on two consecutive reliable visual field tests in at least one eye, which were consistent with the observed optic nerve defects in that eye, as determined by fellowship-trained glaucoma specialists; and (3) all secondary causes of glaucoma excluded. Normal controls were defined as subjects older than 35, without: (1) high myopia (greater than 8.00 diopters); (2) high presbyopia (+8.00 diopters); (3) abnormal visual field; (4) intraocular pressure greater than $21 \mathrm{mmHg}$; (5) neuroretinal rim thinning, excavation, notching or nerve fiber layer defects; (6) optic nerveasymmetry; or (7) a cup-to-disc ratio difference between eyes greater than 0.2. A preliminary masked concordance study among glaucoma specialists at three institutions confirmed a $97 \%$ concordance rate in diagnosis of 120 glaucoma cases and controls. ${ }^{54}$ We collected the below phenotypic measures.

1. Central corneal thickness (300-800 microns): measure of the thickness of the cornea 
2. Cup-to-disc ratio ( $>0-1$, decimal fraction): measure of extent of cupping of the optic nerve in relation to the disc, with a higher ratio indicating greater degeneration of the nerve

3. Intraocular pressure (>0-70 $\mathrm{mmHg}$ ): the fluid pressure within the eye, which often (but not always) is elevated in eyes with POAG. Maximum IOP was defined as the highest documented IOP value for each patient.

4. Mean deviation (-35-+20 dB): quantitative output from a Humphrey visual field test that represents the average of a patient's deviation from the visual sensitivity of age-matched controls at all test locations; lower values indicate greater differences from controls and worsening visual fields

5. Pattern standard deviation $(0-20 \mathrm{~dB})$ : quantitative output from a Humphrey visual field test that quantifies irregularities in the field, with larger values signifying non-uniform sensitivity loss

6. Retinal nerve fiber layer (30-130 microns): mean thickness of the nerve fiber layer, which contains fibers expanding into the optic nerve; lower values typically indicate loss of cells and increased severity of POAG

7. Visual acuity (-0.3-6.0, logMAR units): measure of the clarity of central vision using a Snellen or $\log$ MAR chart. All Snellen values were converted to $\log$ MAR units using a published formula. ${ }^{81}$ We used corrected VA for this analysis.

The distribution of available quantitative phenotypes used for the association analysis is shown in box plots in Extended Figure 2.

\section{Genotyping and Quality Control}

\section{Specimen Collection}


Blood was collected by venipuncture in 10 milliliter purple top tubes with EDTA anticoagulant. These samples were frozen at -20 degrees prior to DNA isolation. For saliva collection, subjects were asked to refrain from smoking, drinking, or eating prior to donating specimens. Two milliliters of saliva per subject were collected in Oragene DISCOVER (OGR-500) self-collection kits (DNA Genotek, Canada). The saliva specimens were mixed with stabilizing reagent within the collection tubes per manufacturer's instructions.

\section{DNA Extraction and Quantitation}

Genomic DNA for all enrolled subjects was extracted from peripheral blood or saliva. DNA was isolated from thawed blood samples using Gentra PureGene kits (Qiagen, Valencia, CA) and included the optional RNase treatment step. DNA from saliva samples was extracted using the prepIT.L2P reagent (cat \# PT-L2P-5, DNA Genotek, Canada) and precipitated with ethanol according to manufacturer's instructions. The saliva DNA samples were RNase treated by double digestion with RNase $\mathrm{A}$ and RNase $\mathrm{T}$ and re-precipitated using ethanol according to the manufacturer's instructions. The concentrations of DNA from blood and saliva samples were determined using the fluorescence-based Quant iT dsDNA Board-Range assay kit (cat \# Q-33130, Life Technologies, CA). Fluorescence was measured with a Tecan Infinite M 200 Pro multimode microplate reader (Tecan, NC).

\section{Genotyping}

A $25 \mu \mathrm{l}$ aliquot of all samples with high-quality DNAs and case/control status were plated for array-based high throughput genotyping. These samples consisted of DNA extracted from blood (67.3\%) and DNA isolated from saliva (32.7\%), as described above. Prior to performing these 
studies, the UPenn and Illumina labs demonstrated a $99.996 \%$ concordance rate on this array between blood and saliva. ${ }^{82}$

Genotyping was attempted on 6525 DNA samples using the Multi-Ethnic Genotyping Array (MEGA)V2 (EX) consortium chip on the Infinium iSelect platform by Illumina FastTrack Services (Illumina, San Diego, CA). Standard MEGA array content was supplemented with 5000 SNPs from prior GWAS studies on POAG, common polymorphisms from POAG-associated genes, and variants detected from whole-genome sequencing of POAAGG subjects. At least one sample per 96-well microtiter plate was genotyped in duplicate for purposes of quality control. A total of 6406 samples passed genotyping. The genotype calls were generated using the Genome Studio genotyping module (GT). Cluster optimization and reproducibility analysis for paired samples were performed as per standard practices at Illumina FastTrack services.

\section{Quality Control}

Standard quality assurance/quality control (QA/QC) methods (Extended Table 1,2) for sample and variant quality filtering were applied. ${ }^{83}$ Pre-imputation QC, including a comparison between reported gender and genetically informed sex and 95\% sample and marker call rate filters, was run on 2,040,811 SNPs and 6,525samples. A total of 1,845, 896 variants and 6403 people passed preimputation quality control measures while 775,309 variants were ultimately used for imputations after phasing and strand checks.

\section{Imputation}

Imputation was carried out across the autosomal chromosomes using the full 1000 Genomes

Project Phase 3 reference panel $(\mathrm{N}=2504) .{ }^{84}$ The study samples were imputed together using 
genotyped SNPs passing quality filters as described above, and were first phased using Eagle2 and then imputed using the Michigan Imputation Server v1.0.4 (Minimac 3). ${ }^{85}$ Association analyses were performed on all variants with an info score $>0.3$.

\section{Statistical Analyses}

\section{Single Variant Association Testing}

Case-control analyses were conducted on 5950 DNA samples (2589 cases and 3361 controls) to detect associations with POAG risk. Variants that failed QC based on missingness filter criteria as described in Extended Table 2 were excluded. No samples faild 99\% misisngness call rate filter after imputation. Additionally, we removed 453 related individuals using a priority-based network approach on samplew with pi-hat $>=0.25$. Samples were removed in the following order of priority: samples related to multiple other samples in the dataset, controls, and samples with a high degree of missingness in quantitative traits.

Association analyses were adjusted for the first five principal components (PCs), age, and sex to prevent spurious association and inflation of test statistics due to population structure or confounding factors. The PCs were calculated by running Eigensoft SmartPCA on uncorrelated, QCed SNPs and projected onto an external set of 1000 Genomes samples ${ }^{84}$. The study samples fall along the gradient from the cluster of European to the cluster of African ancestry reference samples, consistent with the expected genetic ancestry from self-identified African American cohort (Extended Data Figure 1).

Single variant, binary association tests were performed genome-wide using a logistic model framework as implemented in the PLATO software package. ${ }^{86}$ Covariates of sex, age at study enrollment, and the first five PCs were included in the model as fixed effects for the entire 
POAG case control and VA logMAR analysis. Age at study enrollment and the first five PCs were included as covariates in the model for the sex-stratified GWAS.

Single variant, quantitative trait association tests were performed genome-wide using generalized estimating equations (GEE) as implemented in the gee $\mathrm{R}$ software package (https://CRAN.R-project.org/package=gee). This method adjusts for the inter-eye correlation for measures taken from both eyes of a subjects and subjects with either one or two eye measurements can be included in GEE analysis. ${ }^{87,88}$ As in the case-control analysis, covariates of sex, age at study enrollment and the first five PCs were included as fixed effects. Outcomes of baseline IOP ( $\mathrm{n}=5282$ samples), maximum IOP ( $\mathrm{n}=5282$ samples), baseline CDR ( $\mathrm{n}=5049$ samples), 'latest' central CCT ( $n=2616$ samples), baseline visual acuity ( $n=5483$ samples), baseline mean deviation (MD baseline, $n=2213$ samples), baseline pattern standard deviation (PSD baseline, $n=2211$ samples) and baseline retinal nerve fiber layer (RNFL, $n=2239$ samples) were tested in all individuals for whom measurements were available.

Samples passing QC with non-missing information for all covariates were included in the association tests. Calibration of the association tests was examined using QQ plots and the genomic control inflation factor, ${ }^{89}$ calculated as the ratio of the median observed test statistic to the median expected test statistic; a value of 1 indicates the observed and expected median test statistics are equivalent. Variants were considered statistically significant if the estimated score test p-value < $5 \times 10^{-8}$. Additionally, odds ratios and standard errors were estimated for the four significant or suggestive variants from the case-control GWAS using the Wald test. Post-GWAS, we evaluated all results were evaluated using FUMA ${ }^{90}$ web-based tool. Gene based analyses using MAGMA was performed using FUMA, SNPs in our results were mapped to 18,991 genes. All genes below Bonferroni corrected p-value $(0.05 / 18991=2.63 \mathrm{e}-06)$ were reported as significant. 


\section{In silico analyses for gene function in ocular tissue databases:}

To understand the functional relevance of genes associated with POAG in our study, we evaluated expression of the genes that contained associated credible set variants in human ocular tissues using a publicly available database: the OTDB (https://genome.uiowa.edu/otdb/). ${ }^{58}$ The OTDB consists of gene expression data for eye tissues from 20 normal human donors generated using Affymetrix Human Exon 1.0 ST arrays. ${ }^{58}$ The gene expression is described as Affymetrix Probe Logarithmic Intensity Error (PLIER) values where individual gene expression values are normalized to expression in other tissues.

We assessed the gene expression in mouse ocular tissues using a publicly available domain "Glaucoma Discovery Platform" (http://glaucomadb.jax.org/glaucoma). ${ }^{59}$ This platform provides an interactive way to analyze RNA sequencing data obtained from RGCs isolated from retina and optic nerve head of 9-month-old female D2 mouse (an age-dependent model of ocular hypertension/glaucoma), and D2-Gpnmb ${ }^{+}$mouse (that does not develop high IOP/glaucoma). ${ }^{91}$ In this study, four distinct groups of D2 and D2-Gpnmb ${ }^{+}$mice were compared based on the axonal degeneration, and gene expression patterns. The transcriptome of D2 group 1 is identical to the control strain (D2-Gpnmb ${ }^{+}$); and D2 groups 2-4 exhibit increasing levels of molecular changes relevant to axonal degeneration when compared to the control group. ${ }^{92}$

An interactive DATAGAN software queried the transcriptome data from D2 and D2-Gpnmb ${ }^{+}$mice to identify differentially expressed genes in these mouse tissues undergoing molecular changes. ${ }^{59}$ The output data from this software was represented as $\log _{2}$ fold change and $q$-value between different stages of D2 mice and D2.Gpnmb+ (control) samples, with $-q$-Values $<0.05$ considered to be significant. We compared expression profiles of genes associated variants reaching significance in our GWAS study among D2 groups and control group. ${ }^{59}$ Among the genes 
implicated in the $95 \%$ credible set of variants, a few did not have mouse homologs or available data (e.g., LOC105378189, LOC145783, LMX1B, and ZNF280D).

\section{TM and iPSC-RGC cultures}

The primary TM cells were commercially obtained from Sciencell, CA, USA (Cat\#6590) and also as a gift from Dr Markus Kuehn, University of Iowa. ${ }^{42}$ We validated the authenticity of the TM cells by performing MYOC induction experiments with dexamethasone as described previously. ${ }^{42}$ We used Passage 2 (P2) to Passage 4 (P4) primary TM cultures for all our experiments. The RGCs for our studies were derived using small molecules to inhibit BMP, TGF-beta (SMAD) and Wnt signaling to differentiate iPSCs into retinal ganglion cells (RGCs). The generation and characterization of these cells employed a slight modification of protocol from Teotia etal., $2017^{93}$ and is described in Chavali et al., doi: https://doi.org/10.1101/682666 (article in revision).

\section{Evaluating oxidative stress in TM and iPSC-RGCs}

The primary TM cells and induced pluripotent stem cell derived retinal ganglion cells (RGCs) were incubated with increased amounts of $\mathrm{H}_{2} \mathrm{O}_{2}$ overnight before replacing the cultures with complete media. The cells were collected 24 hours after the $\mathrm{H}_{2} \mathrm{O}_{2}$ treatment and levels of few selected gene transcripts form the our GWAS using quantitative RT-PCR and gene expression primers (Supplementary Table) and following previously published protocols. ${ }^{94-96}$ The relative gene expression was compared against control (no treatment) to obtain normalized gene expression. Expression levels $( \pm$ SEM) were calculated by analyzing at least three independent samples with replicate reactions and presented on an arbitrary scale that represents the expression of relevant genes compared to the housekeeping gene ACTB. Increase in Superoxide Dismutase 1 
(SOD1) expression levels served as a positive controls for oxidative stress in the same set of samples.

\section{Ingenuity Pathway Analysis (IPA)}

All the SNPs in genes identified in our case-control association study and endophenotype association study were uploaded into Qiagen's IPA system for core analysis. They were then collapsed with the molecular network found in databases from the brain, neurological tissues, and tissues from eye in the Ingenuity Pathway Knowledge Base (IPKB). ${ }^{97,98}$ IPA was performed to identify canonical pathways, diseases and functions, and gene networks that are most significant to genome-wide association findings from our study, and to categorize differentially expressed genes in specific diseases and their possible functions. The IPA analysis summary includes the associated cellular and molecular functions and development pathways with the predicted p-values of significance. The relevance of associated genes from our POAAGG study are discussed.

\section{Data availability}

Genotype data of POAAGG participants are available from the database of Genotypes and Phenotypes (dbGaP) under accession phs001312. 
References

1. Weinreb, R.N. et al. Primary open-angle glaucoma. Nature reviews.Disease primers 2, 16067 (2016).

2. Tham, Y.C. et al. Global prevalence of glaucoma and projections of glaucoma burden through 2040: a systematic review and meta-analysis. Ophthalmology 121, 2081-2090 (2014).

3. Quigley, H.A. \& Broman, A.T. The number of people with glaucoma worldwide in 2010 and 2020. Br J Ophthalmol 90, 262-7 (2006).

4. Tielsch, J.M., Katz, J., Sommer, A., Quigley, H.A. \& Javitt, J.C. Family history and risk of primary open angle glaucoma. The Baltimore Eye Survey. Arch Ophthalmol 112, 6973 (1994).

5. Munoz, B. et al. Causes of blindness and visual impairment in a population of older Americans: The Salisbury Eye Evaluation Study. Archives of ophthalmology (Chicago, Ill.: 1960) 118, 819-825 (2000).

6. The Advanced Glaucoma Intervention Study (AGIS): 3. Baseline characteristics of black and white patients. Ophthalmology 105, 1137-1145 (1998).

7. Martin, M.J., Sommer, A., Gold, E.B. \& Diamond, E.L. Race and primary open-angle glaucoma. Am J Ophthalmol 99, 383-7 (1985).

8. Janssen, S.F. et al. The vast complexity of primary open angle glaucoma: disease genes, risks, molecular mechanisms and pathobiology. Progress in retinal and eye research 37, 31-67 (2013).

9. Leske, M.C., Connell, A.M., Schachat, A.P. \& Hyman, L. The Barbados Eye Study. Prevalence of open angle glaucoma. Archives of ophthalmology (Chicago, Ill.: 1960) 112, 821-829 (1994).

10. Dielemans, I. et al. The prevalence of primary open-angle glaucoma in a populationbased study in The Netherlands. The Rotterdam Study. Ophthalmology 101, 1851-1855 (1994).

11. Khachatryan, N. et al. Primary Open-Angle African American Glaucoma Genetics (POAAGG) Study: gender and risk of POAG in African Americans. PLoS One 14, e0218804 (2019).

12. Prum, B.E. et al. Primary Open-Angle Glaucoma Preferred Practice Pattern Guidelines. Ophthalmology 123, 41 (2016).

13. Heijl, A., Bengtsson, B., Hyman, L., Leske, M.C. \& Early Manifest Glaucoma Trial, G. Natural history of open-angle glaucoma. Ophthalmology 116, 2271-2276 (2009).

14. Heijl, A. et al. Reduction of intraocular pressure and glaucoma progression: results from the Early Manifest Glaucoma Trial. Arch Ophthalmol 120, 1268-79 (2002).

15. Gordon, M.O. et al. The Ocular Hypertension Treatment Study: baseline factors that predict the onset of primary open-angle glaucoma. Archives of ophthalmology (Chicago, Ill.: 1960) 120, 714-20; discussion 829-30 (2002).

16. Leske, M.C. et al. Risk factors for incident open-angle glaucoma: the Barbados Eye Studies. Ophthalmology 115, 85-93 (2008).

17. O'Brien, J.M. et al. Family History in the Primary Open-Angle African American Glaucoma Genetics Study Cohort. American Journal of Ophthalmology (2018).

18. Teikari, J.M. Genetic factors in open-angle (simple and capsular) glaucoma. A population-based twin study. Acta Ophthalmol (Copenh) 65, 715-20 (1987). 
19. Gottfredsdottir, M.S., Sverrisson, T., Musch, D.C. \& Stefansson, E. Chronic open-angle glaucoma and associated ophthalmic findings in monozygotic twins and their spouses in Iceland. J Glaucoma 8, 134-9 (1999).

20. Liu, Y.\& Allingham, R.R. Major review: Molecular genetics of primary open-angle glaucoma. Experimental eye research 160, 62-84 (2017).

21. Allingham, R.R., Liu, Y. \& Rhee, D.J. The genetics of primary open-angle glaucoma: a review. Experimental eye research 88, 837-844 (2009).

22. Youngblood, H., Hauser, M.A. \& Liu, Y. Update on the genetics of primary open-angle glaucoma. Experimental eye research, 107795 (2019).

23. MacGregor, S. et al. Genome-wide association study of intraocular pressure uncovers new pathways to glaucoma. Nature genetics 50, 1067-1071 (2018).

24. Burdon, K.P. et al. Genome-wide association study identifies susceptibility loci for open angle glaucoma at TMCO1 and CDKN2B-AS1. Nature genetics 43, 574-578 (2011).

25. Gibson, J. et al. Genome-wide association study of primary open angle glaucoma risk and quantitative traits. Molecular vision 18, 1083-1092 (2012).

26. Thorleifsson, G. et al. Common sequence variants in the LOXL1 gene confer susceptibility to exfoliation glaucoma. Science 317, 1397-400 (2007).

27. Thorleifsson, G. et al. Common variants near CAV1 and CAV2 are associated with primary open-angle glaucoma. Nature genetics 42, 906-909 (2010).

28. Wiggs, J.L. et al. Common variants at 9p21 and 8q22 are associated with increased susceptibility to optic nerve degeneration in glaucoma. PLoS genetics $\mathbf{8}$, e1002654 (2012).

29. Vithana, E.N. et al. Genome-wide association analyses identify three new susceptibility loci for primary angle closure glaucoma. Nat Genet 44, 1142-1146 (2012).

30. Nakano, M. et al. Three susceptible loci associated with primary open-angle glaucoma identified by genome-wide association study in a Japanese population. Proceedings of the National Academy of Sciences of the United States of America 106, 12838-12842 (2009).

31. Nakano, M. et al. Common variants in CDKN2B-AS1 associated with optic-nerve vulnerability of glaucoma identified by genome-wide association studies in Japanese. PloS one 7, e33389 (2012).

32. Osman, W., Low, S.K., Takahashi, A., Kubo, M. \& Nakamura, Y. A genome-wide association study in the Japanese population confirms 9p21 and 14q23 as susceptibility loci for primary open angle glaucoma. Human molecular genetics 21, 2836-2842 (2012).

33. Takamoto, M. et al. Common variants on chromosome 9p21 are associated with normal tension glaucoma. PLoS One 7, e40107 (2012).

34. Writing Committee for the Normal Tension Glaucoma Genetic Study Group of Japan Glaucoma, S. et al. Genome-wide association study of normal tension glaucoma: common variants in SRBD1 and ELOVL5 contribute to disease susceptibility. Ophthalmology 117, 1331-8 e5 (2010).

35. Bailey, J.N. et al. Genome-wide association analysis identifies TXNRD2, ATXN2 and FOXC1 as susceptibility loci for primary open-angle glaucoma. Nature genetics 48, 189194 (2016).

36. Hoffmann, T.J. et al. Genome-wide association and admixture analysis of glaucoma in the Women's Health Initiative. Human molecular genetics 23, 6634-6643 (2014). 
37. Bonnemaijer, P.W.M. et al. Genome-wide association study of primary open-angle glaucoma in continental and admixed African populations. Human genetics 137, 847-862 (2018).

38. Liu, Y. et al. Investigation of known genetic risk factors for primary open angle glaucoma in two populations of African ancestry. Invest Ophthalmol Vis Sci 54, 6248-54 (2013).

39. Choquet, H. et al. A multiethnic genome-wide association study of primary open-angle glaucoma identifies novel risk loci. Nature communications 9, 2278-018-04555-4 (2018).

40. Taylor, K.D. et al. Genetic Architecture of Primary Open-Angle Glaucoma in Individuals of African Descent: The African Descent and Glaucoma Evaluation Study III. Ophthalmology 126, 38-48 (2019).

41. Genetics of Glaucoma in People of African Descent, C. et al. Association of Genetic Variants With Primary Open-Angle Glaucoma Among Individuals With African Ancestry. JAMA 322, 1682-1691 (2019).

42. Verkuil, L. et al. SNP located in an AluJb repeat downstream of TMCO1, rs4657473, is protective for POAG in African Americans. Br J Ophthalmol (2019).

43. Collins, D.W. et al. The MT-CO1 V83I Polymorphism is a Risk Factor for Primary Open-Angle Glaucoma in African American Men. Invest Ophthalmol Vis Sci 59, 17511759 (2018).

44. Ramdas, W.D. et al. A genome-wide association study of optic disc parameters. PLoS genetics 6, e1000978 (2010).

45. Fan, B.J., Wang, D.Y., Pasquale, L.R., Haines, J.L. \& Wiggs, J.L. Genetic variants associated with optic nerve vertical cup-to-disc ratio are risk factors for primary open angle glaucoma in a US Caucasian population. Investigative ophthalmology \& visual science 52, 1788-1792 (2011).

46. Pasquale, L.R. et al. CDKN2B-AS1 genotype-glaucoma feature correlations in primary open-angle glaucoma patients from the United States. American Journal of Ophthalmology 155, 342-353.e5 (2013).

47. Springelkamp, H. et al. Meta-analysis of genome-wide association studies identifies novel loci that influence cupping and the glaucomatous process. Nature communications 5, 4883 (2014).

48. Hysi, P.G. et al. Genome-wide analysis of multi-ancestry cohorts identifies new loci influencing intraocular pressure and susceptibility to glaucoma. Nature genetics 46, 1126-1130 (2014).

49. Chen, F. et al. Exome array analysis identifies CAV1/CAV2 as a susceptibility locus for intraocular pressure. Investigative ophthalmology \& visual science 56, 544-551 (2014).

50. Ozel, A.B. et al. Genome-wide association study and meta-analysis of intraocular pressure. Hum Genet 133, 41-57 (2014).

51. Gao, X. et al. A genome-wide association study of central corneal thickness in Latinos. Investigative ophthalmology \& visual science 54, 2435-2443 (2013).

52. Lu, Y. et al. Common genetic variants near the Brittle Cornea Syndrome locus ZNF469 influence the blinding disease risk factor central corneal thickness. PLoS genetics $\mathbf{6}$, e1000947 (2010).

53. Lu, Y. et al. Genome-wide association analyses identify multiple loci associated with central corneal thickness and keratoconus. Nature genetics 45, 155-163 (2013). 
54. Charlson, E.S. et al. The primary open-angle african american glaucoma genetics study: baseline demographics. Ophthalmology 122, 711-20 (2015).

55. Gharahkhani, P. et al. Common variants near ABCA1, AFAP1 and GMDS confer risk of primary open-angle glaucoma. Nature genetics 46, 1120-1125 (2014).

56. Li, Z. et al. A common variant near TGFBR3 is associated with primary open angle glaucoma. Human molecular genetics 24, 3880-3892 (2015).

57. Wiggs, J.L. \& Pasquale, L.R. Genetics of glaucoma. Human molecular genetics 26, R21R27 (2017).

58. Wagner, A.H. et al. Exon-level expression profiling of ocular tissues. Exp Eye Res 111, 105-11 (2013).

59. Howell, G.R., Walton, D.O., King, B.L., Libby, R.T. \& John, S.W. Datgan, a reusable software system for facile interrogation and visualization of complex transcription profiling data. BMC Genomics 12, 429 (2011).

60. Davis, B.M., Crawley, L., Pahlitzsch, M., Javaid, F. \& Cordeiro, M.F. Glaucoma: the retina and beyond. Acta Neuropathol 132, 807-826 (2016).

61. Agarwal, R., Gupta, S.K., Agarwal, P., Saxena, R. \& Agrawal, S.S. Current concepts in the pathophysiology of glaucoma. Indian J Ophthalmol 57, 257-66 (2009).

62. Wang, X.D. et al. Vitamin B6 protects primate retinal neurons from ischemic injury. Brain Res 940, 36-43 (2002).

63. Chowdhury, R., Laboissonniere, L.A., Wester, A.K., Muller, M. \& Trimarchi, J.M. The Trim family of genes and the retina: Expression and functional characterization. PLoS One 13, e0202867 (2018).

64. de Leeuw, C.A., Mooij, J.M., Heskes, T. \& Posthuma, D. MAGMA: generalized gene-set analysis of GWAS data. PLoS Comput Biol 11, e1004219 (2015).

65. Schuettauf, F. et al. Neuroprotective effects of cardiotrophin-like cytokine on retinal ganglion cells. Graefes Arch Clin Exp Ophthalmol 243, 1036-42 (2005).

66. Jakobs, T.C. Differential gene expression in glaucoma. Cold Spring Harb Perspect Med 4, a020636 (2014).

67. Hattermann, K. et al. The chemokine receptor CXCR7 is highly expressed in human glioma cells and mediates antiapoptotic effects. Cancer Res 70, 3299-308 (2010).

68. Cornes, B.K. et al. Identification of four novel variants that influence central corneal thickness in multi-ethnic Asian populations. Hum Mol Genet 21, 437-45 (2012).

69. Duhachek-Muggy, S. \& Zolkiewska, A. ADAM12-L is a direct target of the miR-29 and miR-200 families in breast cancer. BMC Cancer 15, 93 (2015).

70. Wiggs, J.L. et al. Variations in COL15A1 and COL18A1 influence age of onset of primary open angle glaucoma. Clin Genet 84, 167-74 (2013).

71. Liu, P. \& Johnson, R.L. Lmx 1 b is required for murine trabecular meshwork formation and for maintenance of corneal transparency. Dev Dyn 239, 2161-71 (2010).

72. Cross, S.H. et al. A dominant-negative mutation of mouse Lmx1b causes glaucoma and is semi-lethal via LDB1-mediated dimerization [corrected]. PLoS Genet 10, e1004359 (2014).

73. Steele, M.R., Inman, D.M., Calkins, D.J., Horner, P.J. \& Vetter, M.L. Microarray analysis of retinal gene expression in the DBA/2J model of glaucoma. Invest Ophthalmol Vis Sci 47, 977-85 (2006).

74. Daniels, R.H., Hall, P.S. \& Bokoch, G.M. Membrane targeting of p21-activated kinase 1 (PAK1) induces neurite outgrowth from PC12 cells. EMBO J 17, 754-64 (1998). 
75. Kim, H. et al. Down-regulation of p21-activated serine/threonine kinase 1 is involved in loss of mesencephalic dopamine neurons. Mol Brain 9, 45 (2016).

76. Hinch, A.G. et al. The landscape of recombination in African Americans. Nature 476, 170-175 (2011).

77. Zakharia, F. et al. Characterizing the admixed African ancestry of African Americans. Genome Biology 10, R141 (2009).

78. Simon-Sanchez, J. \& Singleton, A. Genome-wide association studies in neurological disorders. The Lancet.Neurology 7, 1067-1072 (2008).

79. Kidd, J.M. et al. Population genetic inference from personal genome data: impact of ancestry and admixture on human genomic variation. American Journal of Human Genetics 91, 660-671 (2012).

80. Harris, P.A. et al. Research electronic data capture (REDCap)--a metadata-driven methodology and workflow process for providing translational research informatics support. Journal of Biomedical Informatics 42, 377-381 (2009).

81. Holladay, J.T. Visual acuity measurements. J Cataract Refract Surg 30, 287-90 (2004).

82. Gudiseva, H.V. et al. Saliva DNA quality and genotyping efficiency in a predominantly elderly population. BMC Med Genomics 9, 17 (2016).

83. Laurie, C.C. et al. Quality control and quality assurance in genotypic data for genomewide association studies. Genetic epidemiology 34, 591-602 (2010).

84. Genomes Project, C. et al. A global reference for human genetic variation. Nature 526, 68-74 (2015).

85. Das, S. et al. Next-generation genotype imputation service and methods. Nat Genet $\mathbf{4 8}$, 1284-1287 (2016).

86. Chen, H. et al. Control for Population Structure and Relatedness for Binary Traits in Genetic Association Studies via Logistic Mixed Models. American Journal of Human Genetics 98, 653-666 (2016).

87. Ying, G.-s., Maguire, M.G., Glynn, R. \& Rosner, B. Tutorial on Biostatistics: Linear Regression Analysis of Continuous Correlated Eye Data. Ophthalmic Epidemiology 24, 130-140 (2017).

88. Ying, G.-s., Maguire, M.G., Glynn, R. \& Rosner, B. Tutorial on Biostatistics: Statistical Analysis for Correlated Binary Eye Data. Ophthalmic Epidemiology 25, 1-12 (2018).

89. Devlin, B. \& Roeder, K. Genomic control for association studies. Biometrics 55, 9971004 (1999).

90. Watanabe, K., Taskesen, E., van Bochoven, A. \& Posthuma, D. Functional mapping and annotation of genetic associations with FUMA. Nat Commun 8, 1826 (2017).

91. Libby, R.T. et al. Inherited glaucoma in DBA/2J mice: pertinent disease features for studying the neurodegeneration. Vis Neurosci 22, 637-48 (2005).

92. Williams, P.A. et al. Vitamin B3 modulates mitochondrial vulnerability and prevents glaucoma in aged mice. Science 355, 756-760 (2017).

93. Teotia, P. et al. Generation of Functional Human Retinal Ganglion Cells with Target Specificity from Pluripotent Stem Cells by Chemically Defined Recapitulation of Developmental Mechanism. Stem Cells 35, 572-585 (2017).

94. Tezel, G. et al. Oxidative stress and the regulation of complement activation in human glaucoma. Invest Ophthalmol Vis Sci 51, 5071-82 (2010). 
95. Benoist d'Azy, C., Pereira, B., Chiambaretta, F. \& Dutheil, F. Oxidative and AntiOxidative Stress Markers in Chronic Glaucoma: A Systematic Review and MetaAnalysis. PLoS One 11, e0166915 (2016).

96. Wang, M. \& Zheng, Y. Oxidative stress and antioxidants in the trabecular meshwork. PeerJ 7, e8121 (2019).

97. Kramer, A., Green, J., Pollard, J., Jr. \& Tugendreich, S. Causal analysis approaches in Ingenuity Pathway Analysis. Bioinformatics 30, 523-30 (2014).

98. Danford, I.D. et al. Characterizing the "POAGome": A bioinformatics-driven approach to primary open-angle glaucoma. Prog Retin Eye Res 58, 89-114 (2017). 


\section{Case/Control GWAS}

$10-$
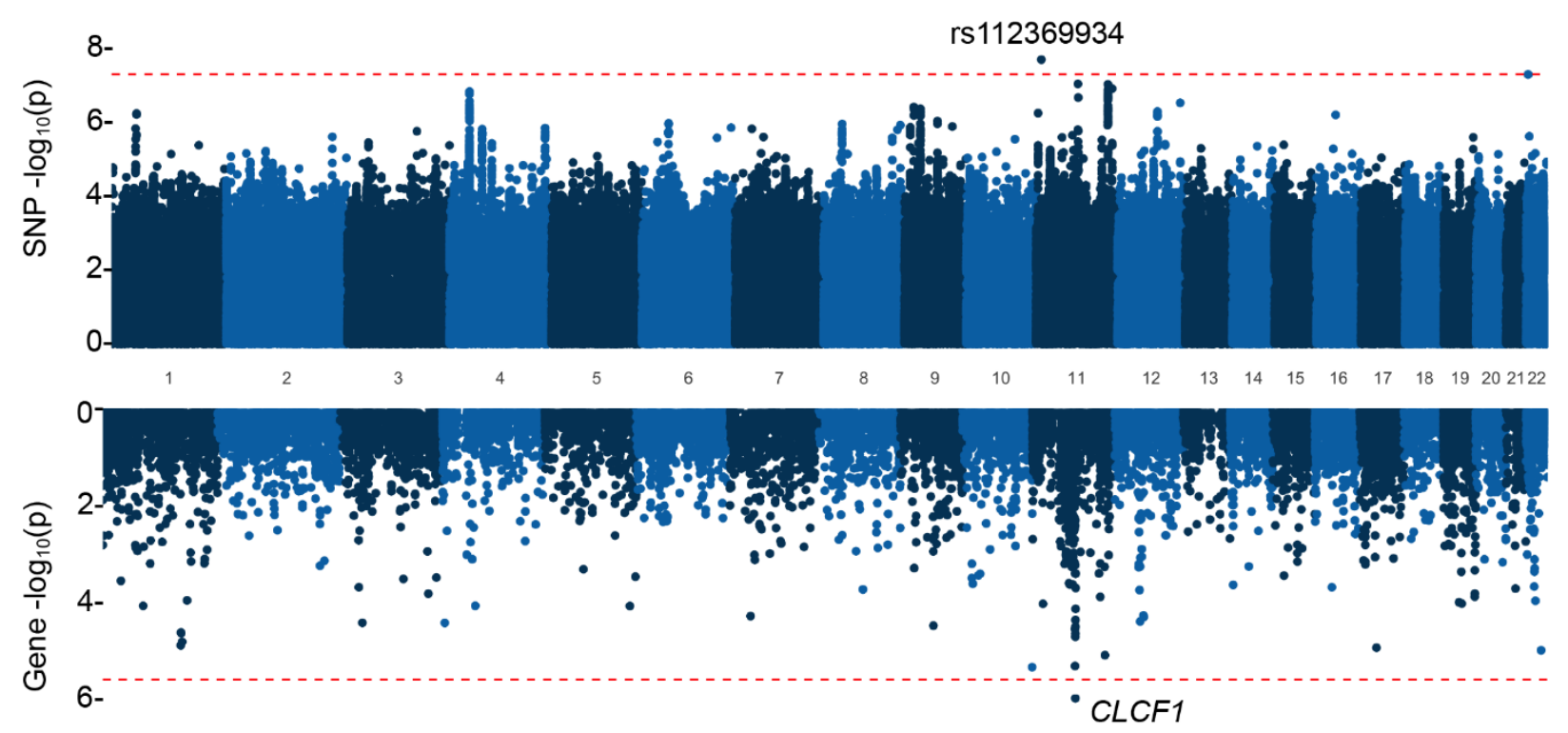

8-

Fig. 1: Genome-wide manhattan plots for case-control analyses. These analyses include results from case control analysis. The SNP association results are displayed in the top portion of each plot, while the association results from gene-based analyses using MAGMA are shown in the bottom portion. Genomewide Manhattan plots display $-\log _{10}$ (p-values) of the logistic regression model testing the association of glaucoma status, stratified by sex, in the set of imputed variants with MAF $>1 \%$. The dotted line indicates genome-wide significance, considered here as $5 \times 10^{-8}$. Gene-based Manhattan plots display $-\log _{10}(\mathrm{p}-$ values) from MAGMA analyses where SNPs were mapped to 18,991 protein coding genes. The dotted line represents Bonferroni corrected $p$-value threshold $(\mathrm{p}=0.05 / 18991=2.63 \mathrm{e}-06)$. 


\section{LD with GWAS Catalog Known Hits Case/control GWAS}
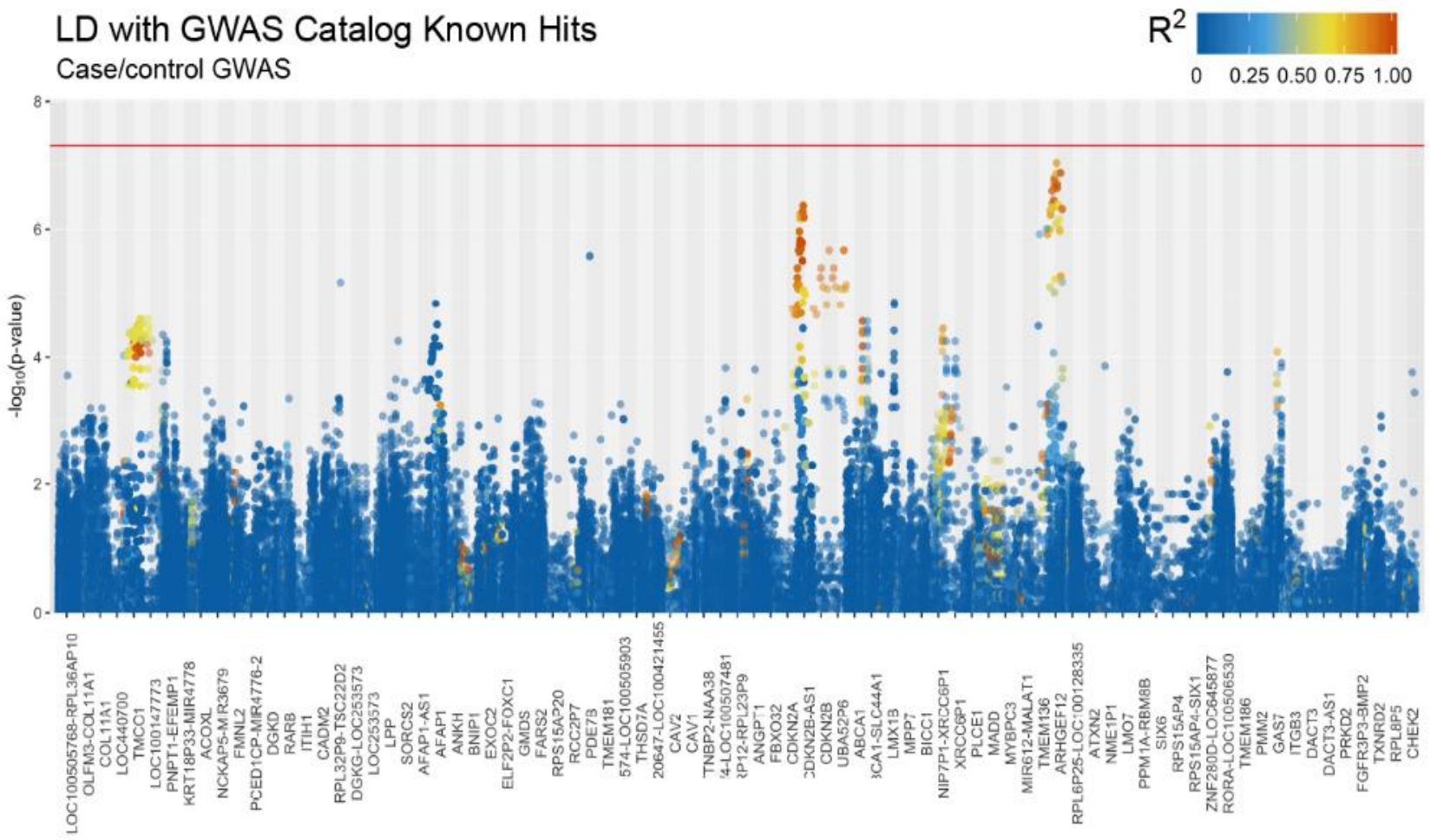

Fig. 2: Manhattan plots displaying -log10 (p-value) of known POAG-associated genes. The points represent $-\log 10$ of p-values of known GWAS hits in case-control POAG analyses.The gradient of each colored point refers to the pairwise linkage disequilibrium R2 with GWAS reported loci. 

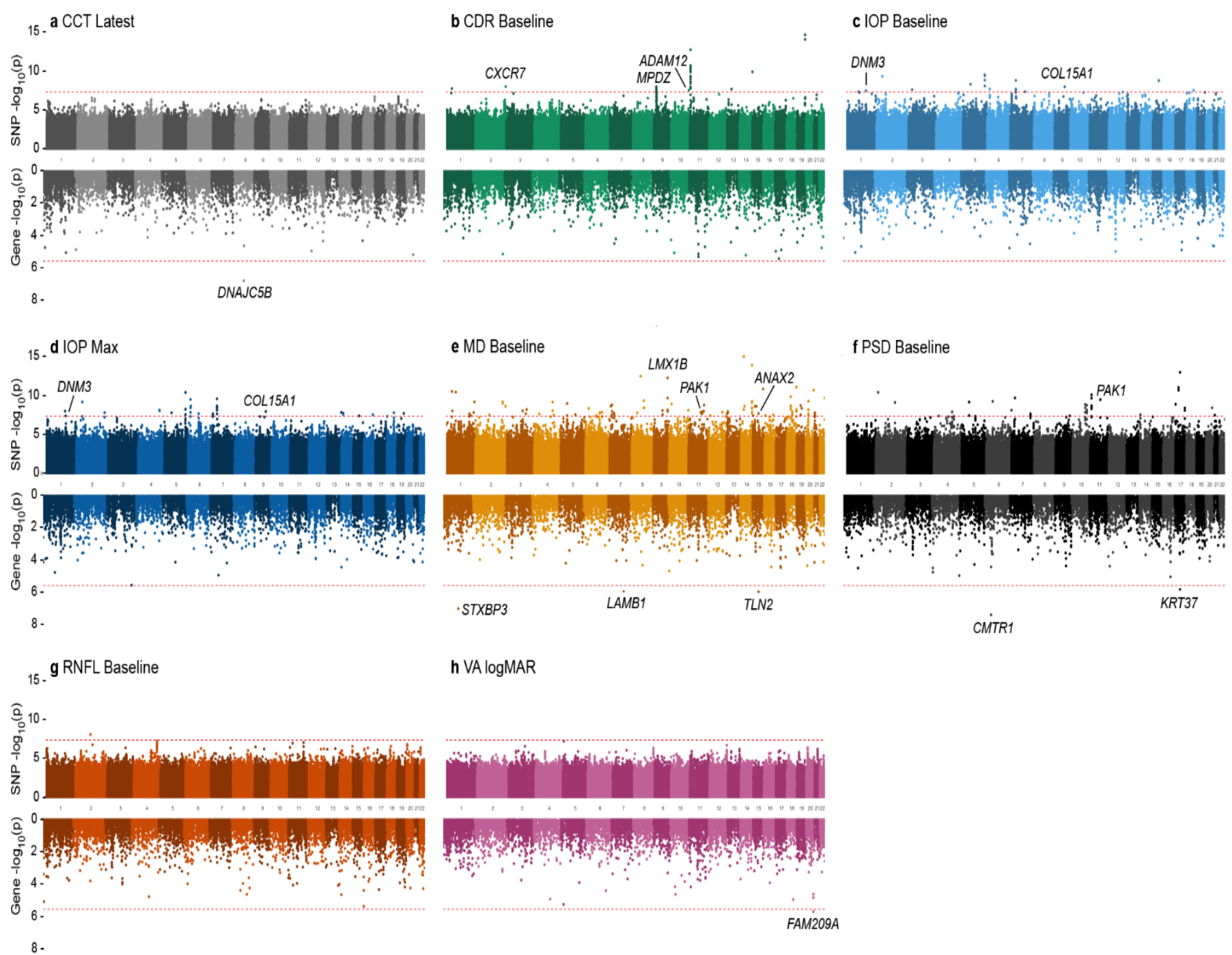

h VA logMAR

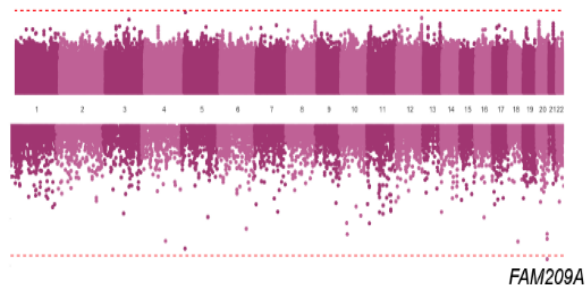

Fig. 3: Genome-wide manhattan plots for quantitative trait analyses. The plots are color-coded by each quantitative trait, including (a) central corneal thickness (CCT) latest, (b) cup-to-disc ratio (CDR) baseline, (c) IOP (intraocular pressure) baseline, (d) IOP maximum, (e) mean deviation (MD) baseline, (f) pattern standard deviation (PSD) baseline, (g) retinal nerve fiber layer (RNFL) baseline, and (h) VA (visual acuity) in LogMAR. The SNP association results are displayed in the top portion of each plot, while the association results from gene-based analyses using MAGMA are shown in the bottom portion. Genome-wide Manhattan plots display $-\log _{10}$ (p-values) of the GEE model testing the association of the traits with the set of imputed variants with MAF $>1 \%$. The dotted line indicates genome-wide significance, considered here as $5 \times 10^{-8}$. Gene-based Manhattan plots display - $\log _{10}$ (p-values) from MAGMA analyses where SNPs were mapped to 18,991 protein coding genes. The dotted line represents Bonferroni corrected $p$-value threshold $(\mathrm{p}=0.05 / 18991=2.63 \mathrm{e}-06)$. 
Table 1. Selected SNPs/genes of interest associated with quantitative traits.

\begin{tabular}{|c|c|c|c|c|c|c|c|}
\hline Phenotype & Chr.Pos & $\begin{array}{c}\text { mapped/ } \\
\text { nearest } \\
\text { gene* }^{*}\end{array}$ & rsID & $p$-value & Beta & $95 \% \mathrm{Cl}$ & MAF \\
\hline \multirow{8}{*}{ CDR } & 11:3521989_T & RPS3AP39 & rs7110375 & $1.83 \mathrm{E}-13$ & -0.06 & $(-0.08,-0.05)$ & 0.068 \\
\hline & 2:237653539_G & CXCR7 & rs 12328841 & 1.05E-08 & -0.03 & $(-0.03,-0.02)$ & 0.422 \\
\hline & 9:13173885_G & MPDZ & rs4740546 & 1.06E-08 & 0.11 & $(0.07,0.15)$ & 0.014 \\
\hline & 9:13194629_T & MPDZ & rs1831533 & $1.63 \mathrm{E}-08$ & 0.11 & $(0.07,0.15)$ & 0.013 \\
\hline & 11:3567134_A & RPS3AP39 & rs146887003 & 1.70E-08 & -0.08 & $(-0.1,-0.05)$ & 0.027 \\
\hline & 9:13181407_A & MPDZ & rs9696052 & $2.22 \mathrm{E}-08$ & 0.11 & $(0.07,0.14)$ & 0.015 \\
\hline & 10:127738557_G & ADAM12 & - & $2.89 \mathrm{E}-08$ & 0.03 & $(0.02,0.03)$ & 0.411 \\
\hline & 9:13183256_A & MPDZ & rs 10733255 & $3.18 \mathrm{E}-08$ & 0.11 & $(0.07,0.15)$ & 0.014 \\
\hline \multirow{3}{*}{$\begin{array}{l}\text { IOP } \\
\text { atBaseline } \\
(\mathrm{mmHg})\end{array}$} & & & rs116365511 & $1.11 \mathrm{E}-08$ & -1.47 & $(-1.98,-0.97)$ & 0.011 \\
\hline & 9:101815916_A & COL15A1 & rs114377702 & $1.11 \mathrm{E}-08$ & -1.47 & $(-1.98,-0.97)$ & 0.011 \\
\hline & 1:172221650_A & DNM3 & rs140007960 & 3.35E-08 & -1.14 & $(-1.54,-0.73)$ & 0.025 \\
\hline \multirow{3}{*}{$\begin{array}{l}\text { Maximum } \\
\text { IOP (mmHg) }\end{array}$} & 9:101816103_A & COL15A1 & rs116365511 & $1.21 \mathrm{E}-08$ & -1.43 & $(-1.93,-0.94)$ & 0.011 \\
\hline & 9:101815916_A & COL15A1 & rs114377702 & $1.21 \mathrm{E}-08$ & -1.43 & $(-1.93,-0.94)$ & 0.011 \\
\hline & 1:172221650_A & DNM3 & rs140007960 & 4.19E-08 & -1.17 & $(-1.59,-0.75)$ & 0.025 \\
\hline \multirow{3}{*}{ MD } & 9:129449650_C & $L M X 1 B$ & rs187699205 & $5.28 \mathrm{E}-13$ & 3.51 & $(2.56,4.47)$ & 0.012 \\
\hline & 6:70670418_C & COL19A1 & rs115364550 & $3.76 \mathrm{E}-08$ & 3.75 & $(2.41,5.08)$ & 0.011 \\
\hline & 11:77190251_C & PAK1 & rs145707826 & $1.62 \mathrm{E}-08$ & 3.82 & $(2.49,5.15)$ & 0.013 \\
\hline PSD & 11:77190646_G & PAK1 & rs370650303 & $3.48 \mathrm{E}-10$ & -1.44 & $(-1.89,-0.99)$ & 0.013 \\
\hline
\end{tabular}

*Mapped/nearest gene=variant in gene region, with nearest gene shaded rsID: dbSNP ID, Beta=effect size, $\mathrm{CI}=$ confidence interval, $\mathrm{CDR}=$ cup-to-disc ratio, $\mathrm{IOP}=$ intraocular pressure, $\mathrm{MD}=$ mean deviation, $\mathrm{PSD}=$ pattern standard deviation. 
Table 2. Assessment of the expression, localization, and differential expression of GWAS-associated SNPs/genes using in silico analysis.

Table 2a: Expression of genes in each locus that comprise over 95\% of GWAS-associated gene variants in adult human eye tissues, as obtained from the Ocular Tissue Database (OTDB), along with gene expression values. In the OTDB, gene expression is represented as an Affymetrix Probe Logarithmic Intensity Error (PLIER) number for an individual probe. These numbers were calculated as described in Wagner et al., 2013.

\begin{tabular}{|l|rrrrrrrrrrr|}
\hline Gene & Probe ID & $\begin{array}{r}\text { Choroid } \\
\text { RPE }\end{array}$ & $\begin{array}{r}\text { Ciliary } \\
\text { Body }\end{array}$ & Cornea & Iris & Lens & $\begin{array}{r}\text { Optic } \\
\text { Nerve }\end{array}$ & $\begin{array}{r}\text { Optic Nerve } \\
\text { Head }\end{array}$ & Retina & $\begin{array}{r}\text { Sclera } \\
\begin{array}{r}\text { Trabecular } \\
\text { Meshwork }\end{array}\end{array}$ \\
\hline COL15A1 & $3.00 \mathrm{E}+06$ & 34.55 & 27.33 & 35.93 & 27.9 & 32.12 & 32.44 & 32.54 & 39.29 & 35.64 & 31.97 \\
DNM3 & $2.00 \mathrm{E}+06$ & 11.68 & 5.97 & 14.67 & 14.04 & 19.67 & 25.98 & 22.12 & 30 & 17.13 & 25.1 \\
ADAM12 & $3.00 \mathrm{E}+06$ & 23.5 & 22.77 & 25.86 & 23.35 & 19.28 & 26.57 & 20.95 & 23.33 & 24.8 & 34.98 \\
MPDZ & $3.00 \mathrm{E}+06$ & 85.28 & 64.35 & 26.63 & 58.37 & 122.56 & 165.49 & 166.36 & 93.26 & 86.54 & 121.89 \\
LMX1B & $3.00 \mathrm{E}+06$ & 29.66 & 25.72 & 40.25 & 23.48 & 24.9 & 27.8 & 26.9 & 27.43 & 32.41 & 30.61 \\
PAK1 & $3.00 \mathrm{E}+06$ & 25.15 & 19.43 & 12.99 & 40.47 & 22.39 & 19 & 17.48 & 25.93 & 17.15 & 19.69 \\
\hline
\end{tabular}

Table 2b: Gene expression levels of genome-wide associated variants in mouse ONH

\begin{tabular}{|c|c|c|c|c|c|c|c|c|c|c|c|c|}
\hline \multirow[b]{2}{*}{ Gene } & \multirow[b]{2}{*}{ Probe Set ID } & \multirow[b]{2}{*}{$\begin{array}{l}\text { Probe } \\
\text { Sets\# }\end{array}$} & \multicolumn{2}{|c|}{ STAGE 1} & \multicolumn{2}{|c|}{ STAGE 2} & \multicolumn{2}{|c|}{ STAGE 3} & \multicolumn{2}{|c|}{ STAGE 4} & \multicolumn{2}{|c|}{ STAGE 5} \\
\hline & & & FC & QV & FC & QV & FC & QV & FC & QV & FC & QV \\
\hline Trim66 & 1456967_at & 1 & -1.040 & 0.758 & -1.040 & 0.453 & $\begin{array}{c}- \\
1.354\end{array}$ & 0.026 & -1.596 & 0.008 & -1.370 & 0.015 \\
\hline Dnm3 & 1436624_at & 5 & -1.286 & 0.183 & -1.624 & 0.002 & -1.67 & 0.002 & -2.887 & 0.000 & -2.544 & 0.000 \\
\hline Adam12 & 1421171_at & 2 & 1.497 & 0.134 & 1.890 & 0.002 & 1.513 & 0.082 & 2.725 & 0.001 & 2.159 & 0.002 \\
\hline Pak1 & 1450070_s_at & 3 & -1.124 & 0.234 & -1.321 & 0.008 & $\begin{array}{c}- \\
1.359\end{array}$ & 0.011 & -1.950 & 0.001 & -1.983 & 0.000 \\
\hline Cxcr7 & 1417625_s_at & 1 & 1.242 & 0.409 & 1.344 & 0.036 & 1.343 & 0.062 & 2.025 & 0.003 & 1.660 & 0.008 \\
\hline Rbfox 1 & 1418314_a_at & 1 & -1.139 & 0.520 & -1.465 & 0.005 & $\begin{array}{c}- \\
1.589\end{array}$ & 0.011 & -2.405 & 0.002 & -3.741 & 0.000 \\
\hline Col15a1 & 1448755_at & 1 & 1.182 & 0.548 & 1.798 & 0.002 & 1.408 & 0.027 & 2.041 & 0.004 & 1.914 & 0.000 \\
\hline Col19a1 & 1421698_a_at & 3 & -1.501 & 0.296 & -1.506 & 0.037 & $\frac{-}{1.128}$ & 0.372 & -1.947 & 0.013 & 1.090 & 0.369 \\
\hline Macrod2 & 1432431_s_at & 4 & -1.061 & 0.729 & 1.062 & 0.397 & 1.64 & 0.001 & 1.302 & 0.015 & 1.246 & 0.062 \\
\hline$M p d z$ & 1418664_at & 4 & -1.057 & 0.627 & -1.124 & 0.074 & -1.14 & 0.060 & -1.091 & 0.232 & 1.070 & 0.281 \\
\hline$L m \times 1 b$ & 1421769_at & 1 & -1.100 & 0.540 & 1.013 & 0.518 & $1 . \overline{8}$ & 0.227 & -1.003 & 0.562 & -1.042 & 0.379 \\
\hline Anxa2 & 1419091_a_at & 1 & 1.332 & 0.029 & 1.625 & 0.000 & 1.969 & 0.000 & 2.051 & 0.000 & 1.830 & 0.000 \\
\hline
\end{tabular}

The above table shows previously published microarray gene expression dataset in optic nerve head punches and was obtained by submitting data into the OTDB database server. The Log2 fold change (FC) shown here compares DBA/2J mice relative to DBA/2J-Gpnmb+ controls at 5 molecularly distinct stages of glaucoma defined using hierarchical clustering. Stages 1, 2 and 3 are early states of glaucoma, and Stages 4 and 5 have eyes with moderate and severe optic nerve damage, respectively. Q-value (QV) shows the significance of the FC of GWAS genes at each stage. 
Table 3. Evaluation of the expression of genes associated with POAG under oxidative stress condition, in (a) induced pluripotent stem cell derived retinal ganglion cells, and (b) and trabecular meshwork (TM) cells.

Table 3a.

\begin{tabular}{|c|c|c|c|c|c|c|}
\hline Gene & Sample & $\begin{array}{c}\text { Target gene } \\
\text { average Ct } \pm \\
\text { SD }\end{array}$ & $\begin{array}{c}\beta \text { actin } \\
\text { average } \\
C t \pm S D\end{array}$ & $\begin{array}{c}\Delta C t \text { (Target } \\
\text { gene average Ct } \\
-\quad \beta \text { actin } \\
\text { average } C t) \pm S D\end{array}$ & $\begin{array}{c}\Delta \Delta C t(\Delta C t \\
\text { treated- } \Delta C t \\
\text { untreated }) \pm \\
\text { SD } \\
\end{array}$ & $\begin{array}{l}\text { Fold difference in } \\
\text { treated relative to } \\
\text { untreated }(\mathrm{Cl})\end{array}$ \\
\hline \multirow{3}{*}{ SOD1 } & $\begin{array}{c}\mathrm{No} \mathrm{H}_{2} \mathrm{O}_{2} \\
\text { (untreated) }\end{array}$ & $27.21 \pm 0.114$ & $17.92 \pm 0.02$ & $9.29 \pm 0.12$ & $0 \pm 0.08$ & $1(0.92-1.08)$ \\
\hline & $\begin{array}{c}325 \mu \mathrm{M} \mathrm{H}_{2} \mathrm{O}_{2} \\
\text { (treated) }\end{array}$ & $27.41 \pm 0.05$ & $16.99 \pm 0.01$ & $10.42 \pm 0.05$ & $1.13 \pm 0.03$ & $0.46(0.44-0.47)$ \\
\hline & $\begin{array}{c}650 \mu \mathrm{M} \mathrm{H} 2 \mathrm{O} 2 \\
\text { (treated) }\end{array}$ & $30.57 \pm 0.06$ & $24.19 \pm 0.15$ & $6.38 \pm 0.16$ & $-2.91 \pm 0.11$ & $7.49(6.71-8.36)$ \\
\hline \multirow{3}{*}{ NRF2 } & $\begin{array}{c}\mathrm{No} \mathrm{H}_{2} \mathrm{O}_{2} \\
\text { (untreated) }\end{array}$ & $23.48 \pm 0.11$ & $17.92 \pm 0.02$ & $5.56 \pm 0.11$ & $0 \pm 0.08$ & $1(0.92-1.08)$ \\
\hline & $\begin{array}{c}325 \mu \mathrm{M} \mathrm{H}_{2} \mathrm{O}_{2} \\
\text { (treated) }\end{array}$ & $23.56 \pm 0.13$ & $16.99 \pm 0.01$ & $6.57 \pm 0.13$ & $1.01 \pm 0.09$ & $0.5(0.45-0.54)$ \\
\hline & $\begin{array}{c}650 \mu \mathrm{M} \mathrm{H} 2 \mathrm{O} 2 \\
\text { (treated) }\end{array}$ & $30.28 \pm 0.333$ & $24.19 \pm 0.15$ & $6.09 \pm 0.36$ & $0.53 \pm 0.26$ & $0.69(0.54-0.89)$ \\
\hline \multirow{3}{*}{ IL6 } & $\begin{array}{c}\mathrm{No}_{2} \mathrm{O}_{2} \\
\text { (untreated) }\end{array}$ & $29.09 \pm 0.065$ & $17.9 \pm 0.15$ & $11.18 \pm 0.17$ & $0 \pm 0.12$ & $1(0.89-1.12)$ \\
\hline & $\begin{array}{c}325 \mu \mathrm{M} \mathrm{H}_{2} \mathrm{O}_{2} \\
\text { (treated) }\end{array}$ & $27.76 \pm 0.02$ & $16.32 \pm 0$ & $11.44 \pm 0.02$ & $0.25 \pm 0.01$ & $0.84(0.48-0.82)$ \\
\hline & $\begin{array}{c}650 \mu \mathrm{M} \mathrm{H} 2 \mathrm{O} 2 \\
\text { (treated) }\end{array}$ & $37.55 \pm 0.64$ & $26.32 \pm 0.04$ & $11.23 \pm 0.64$ & $0.04 \pm 0.45$ & $0.97(0.93-1.49)$ \\
\hline \multirow{3}{*}{ ANAX2 } & $\begin{array}{c}\mathrm{No} \mathrm{H}_{2} \mathrm{O}_{2} \\
\text { (untreated) } \\
\end{array}$ & $18.96 \pm 0.057$ & $17.68 \pm 0.36$ & $1.28 \pm 0.37$ & $0 \pm 0.26$ & $1(0.78-1.29)$ \\
\hline & $\begin{array}{c}325 \mu \mathrm{M} \mathrm{H}_{2} \mathrm{O}_{2} \\
\text { (treated) }\end{array}$ & $18.71 \pm 0.09$ & $16.04 \pm 0.16$ & $2.67 \pm 0.18$ & $1.39 \pm 0.13$ & $0.38(0.48-0.82)$ \\
\hline & $\begin{array}{c}650 \mu \mathrm{M} \mathrm{H} 2 \mathrm{O} 2 \\
\text { (treated) }\end{array}$ & $24.63 \pm 0.01$ & $22.24 \pm 0.09$ & $2.39 \pm 0.09$ & $1.11 \pm 0.07$ & $0.46(0.93-1.49)$ \\
\hline \multirow{3}{*}{ ADAM12 } & $\begin{array}{c}\mathrm{No} \mathrm{H}_{2} \mathrm{O}_{2} \\
\text { (untreated) }\end{array}$ & $25.67 \pm 0.1$ & $17.68 \pm 0.36$ & $7.99 \pm 0.37$ & $0 \pm 0.26$ & $1(0.77-1.3)$ \\
\hline & $\begin{array}{c}325 \mu \mathrm{M} \mathrm{H}_{2} \mathrm{O}_{2} \\
\text { (treated) }\end{array}$ & $22.39 \pm 0.05$ & $16.04 \pm 0.16$ & $6.35 \pm 0.17$ & $-1.64 \pm 0.12$ & $3.12(2.77-3.5)$ \\
\hline & $\begin{array}{c}650 \mu \mathrm{M} \mathrm{H} 2 \mathrm{O} 2 \\
\text { (treated) }\end{array}$ & $30.76 \pm 0.12$ & $22.24 \pm 0.09$ & $8.52 \pm 0.15$ & $0.52 \pm 0.11$ & $0.7(0.63-0.77)$ \\
\hline \multirow{3}{*}{ COL15A1 } & $\begin{array}{c}\mathrm{No} \mathrm{H}_{2} \mathrm{O}_{2} \\
\text { (untreated) }\end{array}$ & $31.37 \pm 0.01$ & $17.68 \pm 0.36$ & $13.69 \pm 0.36$ & $0 \pm 0.26$ & $1(0.78-1.28)$ \\
\hline & $\begin{array}{c}325 \mu \mathrm{M} \mathrm{H}_{2} \mathrm{O}_{2} \\
\text { (treated) }\end{array}$ & $31.02 \pm 0.43$ & $16.04 \pm 0.16$ & $14.98 \pm 0.46$ & $1.29 \pm 0.33$ & $0.41(0.3-0.56)$ \\
\hline & $\begin{array}{c}650 \mu \mathrm{M} \mathrm{H} 2 \mathrm{O} 2 \\
\text { (treated) }\end{array}$ & $31.8 \pm 0.13$ & $22.24 \pm 0.09$ & $9.55 \pm 0.16$ & $-4.14 \pm 0.11$ & $17.6(15.76-19.66)$ \\
\hline \multirow{3}{*}{ COL19A1 } & $\begin{array}{c}\mathrm{No}_{2} \mathrm{O}_{2} \\
\text { (untreated) }\end{array}$ & $34.59 \pm 0.67$ & $17.68 \pm 0.36$ & $16.91 \pm 0.76$ & $0 \pm 0.54$ & $1(0.59-1.7)$ \\
\hline & $\begin{array}{c}325 \mu \mathrm{M} \mathrm{H}_{2} \mathrm{O}_{2} \\
\text { (treated) }\end{array}$ & $32.12 \pm 0.012$ & $16.04 \pm 0.16$ & $16.08 \pm 0.16$ & $-0.83 \pm 0.11$ & $1.77(1.59-1.98)$ \\
\hline & $\begin{array}{c}650 \mu \mathrm{M} \mathrm{H} 2 \mathrm{O} 2 \\
\text { (treated) }\end{array}$ & $35.81 \pm 0$ & $22.24 \pm 0.09$ & $13.57 \pm 0.09$ & $-3.34 \pm 0.07$ & $10.13(9.49-10.8)$ \\
\hline \multirow{3}{*}{ CXCR7 } & $\begin{array}{c}\mathrm{No}_{2} \mathrm{O}_{2} \\
\text { (untreated) } \\
\end{array}$ & $20.93 \pm 0.032$ & $17.68 \pm 0.36$ & $3.25 \pm 0.36$ & $0 \pm 0.26$ & $1(0.78-1.29)$ \\
\hline & $\begin{array}{c}325 \mu \mathrm{M} \mathrm{H}_{2} \mathrm{O}_{2} \\
\text { (treated) }\end{array}$ & $20.87 \pm 0.09$ & $16.04 \pm 0.16$ & $4.83 \pm 0.19$ & $1.58 \pm 0.13$ & $0.33(0.29-0.38)$ \\
\hline & $\begin{array}{c}650 \mu \mathrm{M} \mathrm{H} 2 \mathrm{O} 2 \\
\text { (treated) }\end{array}$ & $26.42 \pm 0.06$ & $22.24 \pm 0.09$ & $4.17 \pm 0.11$ & $0.92 \pm 0.08$ & $0.53(0.49-0.57)$ \\
\hline
\end{tabular}




\begin{tabular}{|c|c|c|c|c|c|c|}
\hline \multirow{3}{*}{ DNM3 } & $\begin{array}{c}\mathrm{No}_{2} \mathrm{O}_{2} \\
\text { (untreated) }\end{array}$ & $25.56 \pm 0.237$ & $17.68 \pm 0.36$ & $7.88 \pm 0.43$ & $0 \pm 0.31$ & $1(0.74-1.35)$ \\
\hline & $\begin{array}{c}325 \mu \mathrm{M} \mathrm{H} \mathrm{H}_{2} \\
\text { (treated) }\end{array}$ & $26.3 \pm 0.37$ & $16.04 \pm 0.16$ & $10.26 \pm 0.4$ & $2.38 \pm 0.28$ & $0.19(0.15-0.25)$ \\
\hline & $\begin{array}{c}650 \mu \mathrm{M} \mathrm{H} 2 \mathrm{O} 2 \\
\text { (treated) }\end{array}$ & $27.46 \pm 0.05$ & $22.24 \pm 0.09$ & $5.22 \pm 0.1$ & $-2.66 \pm 0.07$ & $6.33(5.89-6.8)$ \\
\hline \multirow{3}{*}{$L M X 1 B$} & $\begin{array}{c}\mathrm{No}_{2} \mathrm{H}_{2} \\
\text { (untreated) }\end{array}$ & $32.32 \pm 0.181$ & $17.68 \pm 0.36$ & $14.64 \pm 0.4$ & $0 \pm 0.29$ & $1(0.76-1.32)$ \\
\hline & $\begin{array}{c}325 \mu \mathrm{M} \mathrm{H}_{2} \mathrm{O}_{2} \\
\text { (treated) }\end{array}$ & $32.18 \pm 0.22$ & $16.04 \pm 0.16$ & $16.14 \pm 0.27$ & $1.5 \pm 0.19$ & $0.35(0.29-0.43)$ \\
\hline & $\begin{array}{c}650 \mu \mathrm{M} \mathrm{H} 2 \mathrm{O} 2 \\
\text { (treated) }\end{array}$ & $35.84 \pm 0.25$ & $22.24 \pm 0.09$ & $13.6 \pm 0.27$ & $-1.04 \pm 0.19$ & $2.06(1.71-2.49)$ \\
\hline \multirow{3}{*}{ PAK1 } & $\begin{array}{c}\mathrm{No}_{2} \mathrm{O}_{2} \\
\text { (untreated) }\end{array}$ & $24.06 \pm 0.155$ & $17.68 \pm 0.36$ & $6.38 \pm 0.39$ & $0 \pm 0.28$ & $1(0.76-1.31)$ \\
\hline & $\begin{array}{c}325 \mu \mathrm{M} \mathrm{H}_{2} \mathrm{O}_{2} \\
\text { (treated) }\end{array}$ & $24.2 \pm 0.02$ & $16.04 \pm 0.16$ & $8.16 \pm 0.16$ & $1.78 \pm 0.11$ & $0.29(0.26-0.33)$ \\
\hline & $\begin{array}{c}650 \mu \mathrm{M} \mathrm{H} 2 \mathrm{O} 2 \\
\text { (treated) }\end{array}$ & $29.06 \pm 0.02$ & $22.24 \pm 0.09$ & $6.82 \pm 0.1$ & $0.44 \pm 0.07$ & $0.74(0.69-0.79)$ \\
\hline \multirow{3}{*}{ TRIM66 } & $\begin{array}{c}\mathrm{No} \mathrm{H}_{2} \mathrm{O}_{2} \\
\text { (untreated) }\end{array}$ & $27.95 \pm 0.02$ & $17.68 \pm 0.36$ & $10.27 \pm 0.36$ & $0 \pm 0.26$ & $1(0.78-1.28)$ \\
\hline & $\begin{array}{c}325 \mu \mathrm{M} \mathrm{H}_{2} \mathrm{O}_{2} \\
\text { (treated) }\end{array}$ & $27.28 \pm 0.04$ & $16.04 \pm 0.16$ & $11.24 \pm 0.16$ & $0.98 \pm 0.12$ & $0.51(0.45-0.57)$ \\
\hline & $\begin{array}{c}650 \mu \mathrm{M} \mathrm{H} 2 \mathrm{O} 2 \\
\text { (treated) }\end{array}$ & $30.91 \pm 0.083$ & $22.24 \pm 0.09$ & $8.66 \pm 0.12$ & $-1.6 \pm 0.09$ & $3.04(2.79-3.31)$ \\
\hline
\end{tabular}

Table 5b.

\begin{tabular}{|c|c|c|c|c|c|c|}
\hline Genes & Sample & $\begin{array}{c}\text { Target gene } \\
\text { average Ct } \pm \\
\text { SD }\end{array}$ & $\begin{array}{c}\beta \text { actin } \\
\text { average } \\
C t \pm S D\end{array}$ & $\begin{array}{c}\Delta \mathrm{Ct} \text { (Target } \\
\text { gene average } \\
\mathrm{Ct}-\boldsymbol{\beta} \text { actin } \\
\text { average } \mathrm{Ct}) \pm \\
\mathrm{SD}\end{array}$ & $\begin{array}{c}\Delta \Delta C t(\Delta C t \\
\text { treated- } \Delta C t \\
\text { untreated }) \pm \\
\text { SD }\end{array}$ & $\begin{array}{l}\text { Fold difference } \\
\text { in treated } \\
\text { relative to } \\
\text { untreated }(\mathrm{Cl})\end{array}$ \\
\hline \multirow[t]{2}{*}{ SOD1 } & $\begin{array}{c}\text { No H2O2 } \\
\text { (untreated) }\end{array}$ & $24.33 \pm 0.063$ & $16.13 \pm 0.14$ & $8.2 \pm 0.15$ & $0 \pm 0.11$ & $1(0.9-1.11)$ \\
\hline & $\begin{array}{c}100 \mu \mathrm{M} \mathrm{H} \text { HO2 } \\
\text { (treated) }\end{array}$ & $25.34 \pm 0.05$ & $18.29 \pm 0.09$ & $7.05 \pm 0.1$ & $-1.15 \pm 0.07$ & $2.21(2.06-2.37)$ \\
\hline \multirow[t]{2}{*}{ NRF2 } & $\begin{array}{c}\text { No H2O2 } \\
\text { (untreated) }\end{array}$ & $20.44 \pm 0.376$ & $16.13 \pm 0.14$ & $4.31 \pm 0.4$ & $0 \pm 0.28$ & $1(0.76-1.32)$ \\
\hline & $\begin{array}{c}100 \mu \mathrm{M} \mathrm{H} 2 \mathrm{O} 2 \\
\text { (treated) }\end{array}$ & $22.58 \pm 0.11$ & $18.29 \pm 0.09$ & $4.3 \pm 0.14$ & $-0.01 \pm 0.1$ & $1.01(0.91-1.11)$ \\
\hline \multirow[t]{2}{*}{ IL6 } & $\begin{array}{c}\text { No H2O2 } \\
\text { (untreated) }\end{array}$ & $26.22 \pm 0.061$ & $16.11 \pm 0.01$ & $10.11 \pm 0.06$ & $0 \pm 0.04$ & $1(0.96-1.04)$ \\
\hline & $\begin{array}{c}100 \mu \mathrm{M} \mathrm{H} \text { HO2 } \\
\text { (treated) }\end{array}$ & $29.5 \pm 0.27$ & $20.83 \pm 0.07$ & $8.67 \pm 0.28$ & $-1.44 \pm 0.2$ & 2.71(2.23-3.3) \\
\hline \multirow[t]{2}{*}{$A N X A 2$} & $\begin{array}{c}\text { No H2O2 } \\
\text { (untreated) }\end{array}$ & $19.47 \pm 0.034$ & $16.82 \pm 0.17$ & $2.68 \pm 0.17$ & $0 \pm 0.17$ & $1(0.89-1.12)$ \\
\hline & $\begin{array}{c}100 \mu \mathrm{M} \mathrm{H} 2 \mathrm{O} 2 \\
\text { (treated) }\end{array}$ & $22.76 \pm 0.072$ & $22.64 \pm 0.01$ & $0.17 \pm 0.07$ & $-2.5 \pm 0.07$ & $5.67(5.39-5.97)$ \\
\hline \multirow[t]{2}{*}{$A D A M 12$} & $\begin{array}{c}\text { No H2O2 } \\
\text { (untreated) }\end{array}$ & $24.13 \pm 0.11$ & $16.82 \pm 0.17$ & $7.31 \pm 0.2$ & $0 \pm 0.14$ & $1(0.87-1.15)$ \\
\hline & $\begin{array}{c}100 \mu \mathrm{M} \mathrm{H} \text { (treated) } \\
\text { (treat }\end{array}$ & $29.47 \pm 0.16$ & $22.64 \pm 0.01$ & $6.83 \pm 0.16$ & $-0.48 \pm 0.11$ & $1.4(1.25-1.56)$ \\
\hline
\end{tabular}




\begin{tabular}{|c|c|c|c|c|c|c|}
\hline \multirow[t]{2}{*}{ COL 15A1 } & $\begin{array}{c}\text { No H2O2 } \\
\text { (untreated) }\end{array}$ & $32.55 \pm 0.003$ & $15.73 \pm 0.17$ & $15.73 \pm 0.17$ & $0 \pm 0.12$ & $1(0.89-1.12)$ \\
\hline & $\begin{array}{c}100 \mu \mathrm{M} \mathrm{H} 2 \mathrm{O} 2 \\
\text { (treated) }\end{array}$ & $35.87 \pm 0.01$ & $13.23 \pm 0.02$ & $13.23 \pm 0.02$ & $-2.5 \pm 0.01$ & $5.64(5.56-5.72)$ \\
\hline \multirow[t]{2}{*}{ CXCR7 } & $\begin{array}{c}\text { No } \mathrm{H} 2 \mathrm{O} 2 \\
\text { (untreated) }\end{array}$ & $26.68 \pm 0.227$ & $16.82 \pm 0.17$ & $9.86 \pm 0.28$ & $0 \pm 0.2$ & $1(0.82-1.21)$ \\
\hline & $\begin{array}{c}100 \mu \mathrm{M} \mathrm{H} 2 \mathrm{O} 2 \\
\text { (treated) }\end{array}$ & $27.62 \pm 0.12$ & $22.64 \pm 0.01$ & $4.98 \pm 0.12$ & $-4.88 \pm 0.08$ & $\begin{array}{c}\text { 29.35(27.06- } \\
31.84)\end{array}$ \\
\hline \multirow[t]{2}{*}{ DNM3 } & $\begin{array}{c}\text { No } \mathrm{H} 2 \mathrm{O} 2 \\
\text { (untreated) }\end{array}$ & $31.75 \pm 0.77$ & $16.82 \pm 0.17$ & $14.93 \pm 0.79$ & $0 \pm 0.56$ & $1(0.58-1.73)$ \\
\hline & $\begin{array}{c}100 \mu \mathrm{M} \mathrm{H} 2 \mathrm{O} 2 \\
\text { (treated) }\end{array}$ & $33.8 \pm 0.28$ & $22.64 \pm 0.01$ & $11.16 \pm 0.28$ & $-3.76 \pm 0.2$ & $\begin{array}{c}\mathbf{1 3 . 5 8 ( 1 1 . 1 6 -} \\
16.53)\end{array}$ \\
\hline \multirow[t]{2}{*}{$L M X 1 B$} & $\begin{array}{c}\text { No H2O2 } \\
\text { (untreated) }\end{array}$ & $23.7 \pm 0.176$ & $16.82 \pm 0.17$ & $6.88 \pm 0.24$ & $0 \pm 0.17$ & $1(0.85-1.18)$ \\
\hline & $\begin{array}{c}100 \mu \mathrm{M} \mathrm{H} \text { H2O2 } \\
\text { (treated) }\end{array}$ & $30.39 \pm 0.02$ & $22.64 \pm 0.01$ & $7.75 \pm 0.03$ & $0.87 \pm 0.02$ & $0.55(0.54-0.56)$ \\
\hline \multirow[t]{2}{*}{ PAK1 } & $\begin{array}{c}\text { No } \mathrm{H} 2 \mathrm{O} 2 \\
\text { (untreated) }\end{array}$ & $25.87 \pm 0.094$ & $16.82 \pm 0.17$ & $9.05 \pm 0.19$ & $0 \pm 0.13$ & $1(0.88-1.14)$ \\
\hline & $\begin{array}{c}100 \mu \mathrm{M} \mathrm{H} 2 \mathrm{O} 2 \\
\text { (treated) }\end{array}$ & $27.66 \pm 0.07$ & $22.64 \pm 0.01$ & $5.02 \pm 0.07$ & $-4.02 \pm 0.05$ & $\begin{array}{l}\text { 16.24(15.44- } \\
17.09)\end{array}$ \\
\hline \multirow[t]{2}{*}{ TRIM66 } & $\begin{array}{c}\text { No H2O2 } \\
\text { (untreated) }\end{array}$ & $27.66 \pm 0.08$ & $16.82 \pm 0.17$ & $10.84 \pm 0.18$ & $0 \pm 0.13$ & $1(0.88-1.14)$ \\
\hline & $\begin{array}{c}100 \mu \mathrm{M} \mathrm{H} 2 \mathrm{O} 2 \\
\text { (treated) }\end{array}$ & $31.95 \pm 0$ & $22.64 \pm 0.01$ & $9.31 \pm 0.01$ & $-1.52 \pm 0.01$ & 2.88(2.85-2.91) \\
\hline
\end{tabular}

Fold change $\geq 2$ considered significantly differentially expressed and highlighted in bold. Standard deviation represented as SD 
Table 4: Pathways analysis of POAG-associated genes for various endophenotypes and of genes from MAGMA analysis using ingenuity pathways analysis.

\begin{tabular}{|c|c|c|c|}
\hline Phenotype & Ingenuity Canonical Pathways & $p$-value & genes \\
\hline \multirow{3}{*}{ CDR } & Inhibition of Matrix Metalloproteases* & 0.0069 & ADAM12 \\
\hline & Tight Junction Signaling* & 0.035 & MPDZ \\
\hline & Axonal Guidance Signaling & 0.092 & ADAM12 \\
\hline \multirow{2}{*}{$\begin{array}{l}\text { IOP \& IOP } \\
\max \end{array}$} & Remodeling of Epithelial Adherens Junctions & 0.05 & DNM3 \\
\hline & FAK Signaling & 0.071 & TNS1 \\
\hline \multirow{3}{*}{ MD } & Pyridoxal 5'-phosphate Salvage Pathway* & 0.006 & CDK8,PAK1 \\
\hline & Agrin Interactions at Neuromuscular Junction* & 0.008 & ERBB4,PAK1 \\
\hline & DNA damage-induced $14-3-3 \sigma$ Signaling ${ }^{*}$ & 0.025 & ATR \\
\hline \multirow{7}{*}{ PSD } & Amyotrophic Lateral Sclerosis Signaling* & 0.01 & GRIN2C,PAK1 \\
\hline & Ephrin Receptor Signaling* & 0.0034 & GRIN2C,PAK1 \\
\hline & Synaptogenesis Signaling Pathway* & 0.01 & GRIN2C,PAK1 \\
\hline & Retinol Biosynthesis* & 0.034 & CES4A \\
\hline & Role of Oct4 in Mammalian Embryonic Stem Cell Pluripotency & 0.055 & PHB \\
\hline & Synaptogenesis Signaling Pathway & 0.061 & GOSR1,STXBP3 \\
\hline & Semaphorin Signaling in Neurons & 0.077 & CRMP1 \\
\hline
\end{tabular}

$\mathrm{P}$-value $>0.05$ is significant. $\mathrm{CDR}=$ cup-to-disc ratio, $\mathrm{IOP}=$ intraocular pressure in $\mathrm{mmHg}, \mathrm{MD}=$ mean deviation, $\mathrm{PSD}=$ pattern standard deviation 